Intercomparison of Groundwater Flow Monitoring Technologies at Site OU 1, Former Fort Ord, California

P. F. Daley, J. Jantos, W. H. Pedler, W. A. Mandell

September 21, 2005 
This document was prepared as an account of work sponsored by an agency of the United States Government. Neither the United States Government nor the University of California nor any of their employees, makes any warranty, express or implied, or assumes any legal liability or responsibility for the accuracy, completeness, or usefulness of any information, apparatus, product, or process disclosed, or represents that its use would not infringe privately owned rights. Reference herein to any specific commercial product, process, or service by trade name, trademark, manufacturer, or otherwise, does not necessarily constitute or imply its endorsement, recommendation, or favoring by the United States Government or the University of California. The views and opinions of authors expressed herein do not necessarily state or reflect those of the United States Government or the University of California, and shall not be used for advertising or product endorsement purposes.

This work was performed under the auspices of the U.S. Department of Energy by University of California, Lawrence Livermore National Laboratory under Contract W-7405-Eng-48. 
UCRL-TR-215567

\title{
Intercomparison of Groundwater Flow Monitoring Technologies at Site OU 1, Former Fort Ord, California
}

\section{Final Report}

Contract No. DACA42-02-2-0056

\author{
Paul F. Daley ${ }^{1}$ \\ Jeffrey Jantos ${ }^{2}$ \\ William H. Pedler ${ }^{2}$ \\ Wayne A. Mandell ${ }^{3}$ \\ ${ }^{1}$ Environmental Restoration Division \\ Lawrence Livermore National Laboratory \\ POB 808/L-403 \\ Livermore, CA 94550 \\ ${ }^{2}$ RAS Integrated Subsurface Evaluation, Inc. \\ 311 Rock Ave \\ Golden, CO 80401 \\ ${ }^{3}$ U.S. Army Environmental Center \\ attn: SSIM-AEC-ERA \\ 5179 Hoadley Rd \\ APGEA, MD 21010-5401 \\ Aberdeen Proving Ground, MD
}

August 3, 2005

This work was supported by U.C. Santa Cruz through the U.S. Army Construction Engineering Research Laboratories under Contract No. DACA42-02-2-0056, and by the U.S. Department of Energy under contract No. W-7405-Eng-48. 


\section{ABBREVIATIONS AND ACRONYMS}

$\begin{array}{ll}\text { 1,1,1-TCA } & 1,1,1 \text {-trichloroethane } \\ \text { ftbgs } & \text { feet below ground surface } \\ \text { CCD } & \text { Charge coupled device (an electronic imaging component) } \\ \text { cis-1,2 DCE } & \text { cis-1,2 Dichoroethylene } \\ \text { FDA } & \text { Fire Drill Area } \\ \text { FEC } & \text { Fluid Electrical Conductivity } \\ \text { FO-SVA } & \text { Fort Ord-Salinas Valley Aquitard } \\ \text { ft/d } & \text { feet/day } \\ \text { HPL } & \text { Hydrophysical Logging } \\ \text { ISPFS } & \text { In-Situ Permeable Flow Sensor } \\ \text { LLNL } & \text { Lawrence Livermore National Laboratory } \\ \text { MCL } & \text { Maximum Contaminant Level } \\ \text { MEK } & \text { Methyl ethyl ketone } \\ \text { ug/L } & \text { micrograms/liter } \\ \text { OU 1 } & \text { Operational Unit 1 } \\ \text { ppb } & \text { parts per billion } \\ \text { SCBFM } & \text { Scanning Colloidal Borescope Flow Meter } \\ \text { TCE } & \text { Trichloroethylene }\end{array}$




\section{ACKNOWLEDGMENTS}

This work was supported by U.C. Santa Cruz (UCSC) through the U.S. Army Construction Engineering Research Laboratories (USA-CERL) under Contract No. DACA42-02-2-0056, and by the U.S. Department of Energy under contract No. DE-AC0376SF00098. We thank our collaborators Curt Oldenburg (LBNL), Preston Jordan (LBNL), Grace Su (LBNL), Barry Freifeld (LBNL), Russ Flegal (UCSC), Patrick Mantey (UCSC), Tim Ford (LLNL) and Stan Martins (LLNL) for technical and logistical help. We thank Lora Lee Martin (UCSC), Richard Lampo (USA-CERL), and Jim Gill (UCSC) for support and encouragement. 


\begin{abstract}
This report presents an intercomparison of three groundwater flow monitoring technologies at a trichloroethylene (TCE) groundwater plume at Operational Unit 1 (OU 1) adjacent to the former Fritzsche Army Airfield at the former Fort Ord Army Base, located on Monterey Bay in northern Monterey County, California. Soil and groundwater at this site became contaminated by fuels and solvents that were burned on a portion of OU 1 called the Fire Drill Area (FDA) as part of firefighter training from 1962 and 1985. Contamination is believed to be restricted to the unconfined A-aquifer, where water is reached at a depth of approximately 60 to 80 feet below the ground surface; the aquifer is from 15 to 20 feet in thickness, and is bounded below by a dense clay layer, the Salinas Valley Aquitard.

Soil excavation and bioremediation were initiated at the site of fire training activities in the late 1980s. Since that time a pump-and-treat operation has been operated close to the original area of contamination, and this system has been largely successful at reducing groundwater contamination in this source area. However, a trichloroethylene (TCE) groundwater plume extends approximately $3000 \mathrm{ft}(900 \mathrm{~m})$ to the northwest away from the FDA. In this report, we have augmented flow monitoring equipment permanently installed in an earlier project (Oldenburg et al., 2002) with two additional flow monitoring devices that could be deployed in existing monitoring wells, in an effort to better understand their performance in a nearly ideal, homogeneous sand aquifer, that we expected would exhibit laminar groundwater flow owing to the site's relatively simple hydrogeology.
\end{abstract}

The three flow monitoring tools were the Hydrotechnics ${ }^{\circledR}$ In-Situ Permeable Flow Sensor (ISPFS), the RAS Integrated Subsurface Evaluation Hydrophysical Logging tool (HPL), and the Lawrence Livermore National Laboratory Scanning Colloidal Borescope Flow Meter (SCBFM). All three devices produce groundwater flow velocity measurements, and the ISPFS and SCBFM systems also generate flow direction estimates. The ISPFS probes are permanently installed and are non-retrievable, but produce long-term records with essentially no operator intervention or maintenance. The HPL and SCBFM systems are lightweight, portable logging devices that employ recording of electrical conductivity changes in wells purged with deionized water (HPL), or imaging of colloidal particles traversing the borehole (SCBFM) as the physical basis for estimating the velocity of groundwater flow through monitoring wells.

All three devices gave estimates of groundwater velocity that were in reasonable agreement. However, although the ISPFS produced groundwater azimuth data that correlated well with conventional conductivity and gradient analyses of the groundwater flow field, the SCBFM direction data were in poor agreement. Further research into the reasons for this lack of correlation would seem to be warranted, given the ease of deployment of this tool in existing conventional monitoring wells, and its good agreement with the velocity estimates of the other technologies examined. 


\section{INTRODUCTION}

This report presents groundwater transport data from three independent monitoring technologies deployed in the trichloroethylene (TCE) groundwater plume at Operational Unit 1 (OU 1) at the former Fort Ord Army Base, located on Monterey Bay in northern Monterey County, California. While all three technologies are designed to produce estimates of fluid flow rate, they differ in mode of installation, theory of operation, and types of data produced. Two of the tools examined, the RAS Hydrophysical Logging tool, (HPL), and the Lawrence Livermore National Laboratory Scanning Colloidal Borescope Flow Meter (SCBFM), could be installed in existing boreholes, and produce point estimates (in time), while the third employed permanently installed sensors for long-term logging of flow rate and direction, at the expense of portability (Hydrotechnics ${ }^{B}$ In-Situ Permeable Flow Sensors, ISPFS). The SCBFM and ISPFS produce estimates of both groundwater flow rate and direction, while the HPL produces flow rate estimates only. Although groundwater flow and azimuth data are crucial to the understanding of contaminant transport, determination of these parameters is often costly, indirect, and frequently difficult to verify. There have been many techniques developed to estimate flow in boreholes, but comparatively few studies have attempted to directly compare data from different groundwater flow monitoring tools (Wilson, et al. 2001). The present experiments were deployed at the OU 1 site to provide a nearly ideal, homogeneous hydrogeological environment in which tool performance could be compared.

\section{SITE DESCRIPTION}

We will first offer a brief historical description of the Fort Ord OU 1 site, and refer the reader to Oldenburg et al. (2002) for additional detail.

OU 1 is situated close to the Pacific coast in a sand dune area, consisting of low hills and closed bowls vegetated by scrub oaks and coastal chapparal species. The unconsolidated dune sands extend from the surface to a depth of 90-130 ft (27-40 m); stabilization of the dunes with vegetation is thought to be relatively recent.

The dunes sands are bounded below by interbedded layers of clays and sands of varying thickness. The first water bearing zone is the unconfined A-aquifer, which lies above the Fort Ord-Salinas Valley Aquitard (FO-SVA). This aquitard separates the A-aquifer consisting of dune sand from deeper, confined, aquifers, the shallowest of which is called the 180 -foot aquifer. The water-table depth of the A-aquifer ranges from approximately $70-100 \mathrm{ft}(21-30 \mathrm{~m})$ bgs.

The former Fritzsche Army Airfield is located in the northernmost portion of the former Fort Ord Army Base. The airport fire department trained at a Fire Drill Area (FDA) adjacent to the airport. Fuels and solvents were placed in the burn pit and combusted for firefighter training from 1962 to 1985 . Subsequently, soil and groundwater contamination was discovered in the A-aquifer, consisting of petroleum hydrocarbons, trichloroethylene (TCE), methyl ethyl ketone (MEK), 1,1,1-trichloroethane (1,1,1-TCA), cis-1,2-dichloroethylene (c-1,2-DCE), and minor amounts of related materials. 
In the late 1980's, the site was identified as Fort Ord's Operable Unit 1 (OU 1), and nearsurface contaminated soil was excavated. Deeper contaminated soils in the Fire Drill Area were bioremediated. Soil sampling confirmed that the surface soil cleanup was successful, and a groundwater extraction and treatment system was installed to capture and treat the residual contaminated groundwater. This system significantly reduced all of the contaminant concentrations. By the early 1990's, contaminants other than TCE were generally below the Maximum Contaminant Levels (MCLs) set by the U.S. EPA for drinking water. TCE, however, is still present at levels in the low tens of parts per billion, and is the target of continued remediation. Data obtained from drilling to the northwest of the original plume now indicates the TCE groundwater plume is $3000 \mathrm{ft}$ (900 m) long, or approximately four times the originally characterized length.

In the late 1990s a groundwater flow and geochemical analysis station was installed in the Fire Drill area (Oldenburg et al. 2002; Figure 1). As part of the ongoing performance evaluation of this integrated system, the present work focuses on three groundwater flow sensing technologies.

\section{FLOW MONITORING TOOLS}

Standard approaches to obtaining groundwater flow velocity information involve making hydraulic head measurements in screened boreholes across a site, to determine hydraulic gradients. These are combined with hydraulic conductivity data to estimate the potential flowrate between the points sampled by the boreholes (Darcy's equation). This methodology will provide useful approximations in many instances, but it ultimately depends on the assumption that the available conductivity data accurately reflect the conditions throughout the target site. Moreover, hydraulic conductivity is generally determined by pumping or slug tests, that may undesirably average zones of preferential flow that are the main conduits of contaminant flow (Kearl and Case 1992; Kearl 1997), or generate problematic wastes in aquifers known or suspected to be contaminated. Sensors that do not depend on conductivity data can potentially provide useful flux data for modeling or remediation optimization without the drawbacks of traditional techniques, and provide a useful link between laboratory and field observations.

Alternative methods for determining flow across boreholes included tracer tests and borehole-dilution tests, that are often deployed with zone-isolating packers (Kearl and Case 1992). Spinner or impeller tools are sometimes used to estimate flows, but are most useful where vertical flow is suspected to be substantial; their use is limited by their relatively high stall speeds (Hess 1986; Molz et al. 1989). Hess (1986) and Kerfoot $(1988,1995)$ also presented development of heat-pulse flow meters that are designed to detect three dimensional flow vectors, although convective components may complicate interpretation. Other physical methods include electromagnetic flowmeters (Young et al. 1991), acoustic (SonTek, Inc. 1996) and laser (Momii et al. 1993) Doppler velocimeters and use of radioisotopic tracers (Drost et al. 1968); in some cases tool intercomparisons have been performed (Molz et al. 1989, Wilson 2001), but clearly more studies of this kind are needed. 


\subsection{In Situ Permeable Flow Sensor}

The In Situ Permeable Flow Sensor was developed in the early 1990s at Sandia National Laboratory, Albuquerque to directly measure groundwater flow vectors in unconsolidated, saturated, porous media (Ballard 1996; Ballard et al. 1996). The tool utilizes heat perturbation and advection from a cylindrical surface, that is in turn studded with an array of precision thermistors that measure heat dispersion around the tool due to groundwater flow. In theory, if a thin cylinder has uniform heat flux from its surface, the temperature distribution on the surface will vary as a function of the magnitude of groundwater flow past the surface. Relatively warmer temperatures will be sensed on the downstream side, and relatively cooler temperatures on the upstream side. Romero (1995) derived mathematical functions describing heat distribution of a finite-length heated cylinder in a permeable flow field:

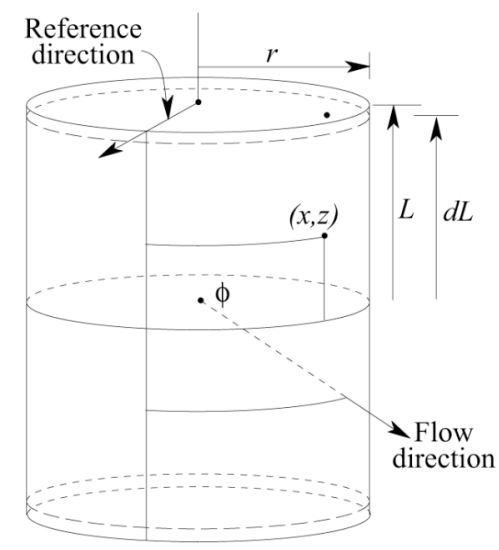

$$
\begin{aligned}
& T(x, z)=Q r / K[1+r / L P e \cos (q-x) \sin \phi] \\
& {\left[\ln \left[2 L / r\left(d^{2}-z^{2}\right)^{1 / 2}\right]-r / L P e \cos (q-x) \sin \phi\right.}
\end{aligned}
$$

$$
\left.+1 / 2 \int_{-\delta}^{\delta} \frac{\mathrm{e}^{1 / 2 \operatorname{Pe}[(\mathrm{z}-\xi) \cos \phi-|\mathrm{z}-\xi|]}}{|\mathrm{z}-\xi|} \mathrm{d} \xi\right] \quad \text { (Eq. 1) }
$$

(figure after Ballard 1996) where $T$ is the temperature at position $x, z$ on the surface of the probe; $x$ is the angular distance in the horizontal plane from the reference direction to the measurement point; $z$ is the distance in the vertical from the midpoint of the probe (dimensionless, by dividing by the half-length of the tool, $L$ ); $r$ is the tool radius; $\delta$ is the half-length of the heated region of the tool, again dimensionless by dividing by $L ; Q$ is the heat flux per unit area from the tool surface; $K$ is thermal conductivity of the saturated porous medium; $P e$ is the dimensionless flow velocity, or Peclet number; $\theta$ is the angular distance in the horizontal plane from the reference direction, and $\phi$ is the angle between vertical and the flow velocity vector. The flow velocity, $P e$ is given by: 


$$
P e=U_{\infty} L \rho \mathrm{c} / K
$$

where $U_{\infty}$ is the magnitude of the Darcy flow velocity far from the tool, $\rho$ is the fluid density, and $\mathrm{c}$ is the fluid specific heat. In practice, the relative deviations of thermistor temperatures from the average for the entire tool temperature are used with a mathematical inversion algorithm to calculate flow vectors.

In the present experiment, the ISPFS were installed approximately 30" above the surface of the FO-SVA clay layer, and a 2" monitoring well was placed adjacent to the thermal probe, with its deepest point approximately 15" above the uppermost part of the ISPFS (Figure 2). The normal practice for installation of these tools is to insert them through a hollow-stem auger, and formation is allowed to collapse around the tool as the auger is withdrawn (Figure 3). Five of the tools were installed during installation of the integrated geochemical analysis station at the FDA; one of the tools suffered an electrical failure within the first few months of its operation (MW-OU1-40-A), and a second has not produced reliable data since its installation (possibly due to incomplete collapse of the formation during installation; MW-OU1-38-A). The remaining three devices have provided reliable data since that time, in good agreement with traditional gradient and conductivity analysis (Jordan et al. 2005); a detailed analysis and simulation of their performance in media with varying thermal properties is provided as part of this project by $\mathrm{Su}$ et al. (2005, and in Press).

\subsection{Hydrophysical Logging Tool}

The hydrophysical logging tool (HPL) has been referred to as fluid-conductivity logging, fluid-electrical-conductivity logging, and ion logging (Cohen 1995). The HPL tool comprises a vertical array of electrical conductivity sensing electrodes and precision thermistors (Figure 4); wells under test are first scanned for ambient properties by recording signals from the sensing elements as the tool is lowered through the borehole fluid. Then, the borehole fluid is slowly replaced with deionized water at a rate that does not change the pressure head. Finally, the fluid electrical conductivity and temperature of the borehole fluid is recorded through repeated vertical scanning over a period of many hours following emplacement of the low-conductivity fluid, as formation water displaces fluids from the borehole; in essence the technique is a specialized instance of borehole tracer dilution, where in this case, the tracer is deionized water, as described by Drost et al. (1968) and Tsang et al. (1990).

Inflow parameters are estimated following the general methods of Drost et al. (1968), although the application of dilution theory to borehole logging is innovative, and has been shown practical for the identification of restricted infiltration zones (Tsang et al. 1990). The tracer is assumed to be uniformly placed in the borehole; its concentration, $\mathrm{C}_{\mathrm{obs}}$, is modified by influx of formation water at concentration $\mathrm{C}_{\mathrm{f}}$, flowing into the borehole at a velocity $v^{*}$, as shown below (after Wilson et al. 2001): 


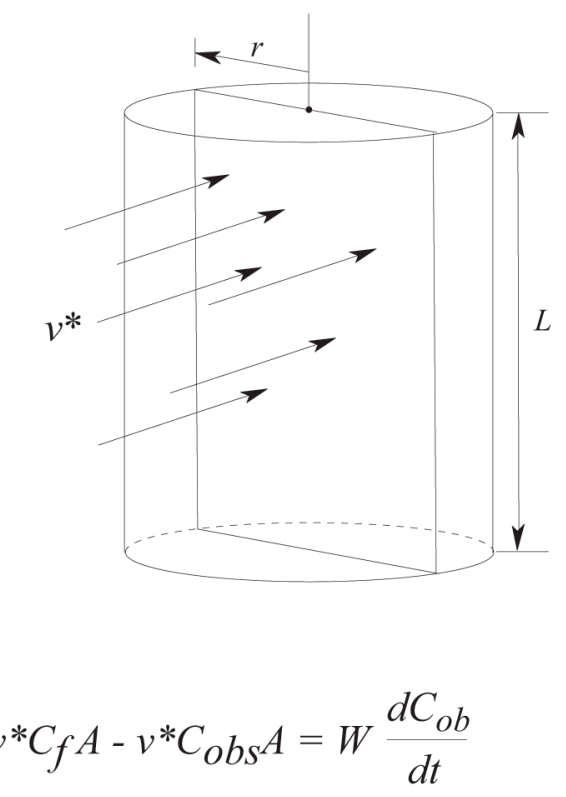

where $A$ is the borehole cross-sectional area $(A=2 r L, r$ is the radius of the borehole, $L$ is the length), and $\mathrm{W}$ is the corresponding volume $(W=\pi \mathrm{r} 2 L)$. If the substitution is made:

$$
\left.C=C_{f}-C_{o b} S \quad \text { (Eq. } 4\right)
$$

equation can be rearranged:

$$
v^{*} C=\frac{W}{A} \frac{d C}{d t}
$$

that can be rearranged to solve for $C$ :

$$
C=C_{0} \exp \left(-\frac{2 t}{\pi r} v^{*}\right)
$$

where $C_{0}$ is $\mathrm{C}$ at $\mathrm{t}=0$, or $C_{f}-C_{o b s}$ at $\mathrm{t}=0$. Taking the natural logarithm of both sides gives:

$$
\ln \left(\frac{C}{C_{0}}\right)=-\frac{2 v^{*}}{\pi r} t
$$

and the ratio $C / C_{0}$ should produce a linear semi-log plot, the slope of which is proportional to the velocity of fluid flowing through the well: 


$$
v^{*}=\frac{\pi r \ln \left(\frac{C_{2}}{C_{1}}\right)}{2\left(t_{2}-t_{1}\right)}
$$

where $t_{1}$ and $t_{2}$ are the times corresponding to $C_{1}$ and $C_{2}$ on the semi-log plot. This velocity corresponds to the measured fluid velocity through the borehole; this may differ from the actual formation flow rate, as flow lines tend to converge toward the borehole, and corrections for these phenomena have been offered (Drost et al. 1968):

$$
q=\frac{v^{*}}{\alpha}
$$

where $q$ is the specific discharge of groundwater in the aquifer, and $\alpha$ is a factor that corrects for convergence of flow in the borehole. The latter factor can only be calculated with a detailed knowledge of the casing screen, sandpack characteristics, and hydraulic properties of the aquifer. However, it is thought to be generally insensitive to formation hydraulic properties as long as the screen and sandpack are substantially more permeable than the formation. When $\alpha$ cannot be calculated directly, formation flow estimates are made using convergence factors of 2.5 to 4 (Momii et al. 1993; Wilson et al. 2001). In the present work, these corrections have not been made, and only "in borehole" flowrates $\left(v^{*}\right)$ are presented.

\subsection{Scanning Colloidal Borescope Flow Meter}

The colloidal borescope developed in the early 1990s at the Oak Ridge National Laboratory (Kearl et al. 1992; Kearl 1997). The instrument described in the Oak Ridge system is very similar to an earlier device that was the subject of a patent (Foster and Fryda 1990), the principal differences being the type of illumination (laser vs. lamp) and imaging device ("Optiram" vs. CCD camera for the Foster and Fyda, and Kearl versions, respectively). The tool consists of a downward-viewing camera with a microscope objective, a source of illumination directed towards the camera, creating a "bright-field" effect, a magnetometer to detect tool orientation, supporting cables, and a viewer/recorder package at the well head. Video recordings are made once the tool has been lowered to the target depth, and colloidal scale particles, in the size range of $2-20 \mu$, are detected as dark objects; if nearly laminar flow is detected (particles stay within the quite thin plane of focus for much or all of their traverse across the viewing field) many particles can contribute to a single reading. Computer software is then used to detect the particles, match them between subsequent frames, and calculate their velocity and direction (Kearl and Roemer 1998). The magnetometer output is recorded at each depth to correct azimuth estimates, as twisting of the tool is unavoidable when using flexible cables to suspend the instrument.

The LLNL scanning colloidal borescope adds an additional feature to the basic design of the Kearl and Foster and Fyda instruments: the plane of focus is continuously adjustable over a distance of almost 1/2 meter, so that once the tool has been placed at a target depth, a range of image "planes" can be visualized without movement of the tool. This is 
thought to offer more flexibility in locating optimum particle fields for logging without creating turbulence as the tool is repositioned.

Because the SCBFM directly visualizes particle transport across the borehole, velocities are estimated using only simple calibrations of the camera objective. However, the tool is subject to the same biases as the HPL and other borehole-deployed devices, in that the presence of the sandpack and screens unavoidably alter flow lines near the well. Kearl (1997) has stated that borescope measurements in the field should be reduced by a factor of from one to four to calculate fluid velocities in adjacent aquifers, and that the observed velocities represent an upper limit to true aquifer flowrates.

\section{RESULTS}

\subsection{ISPFS}

Three of the ISPFSs installed in 1999 have produced reasonable data since that time, and data extracted from these devices, associated with MW-OU1-36-A, MW-OU1-37-A, and MW-OU1-39-A, are discussed in this report. Detailed analyses of the entire records for these sensors, and how their data correlates with aquifer characteristics at the site, are presented in a companion report (Jordan et al. 2005). Preliminary evaluation of ISPFS data from the site indicated suspiciously large vertical components to groundwater flow; in some cases downward vectors were calculated to be as large, or larger than the horizontal vectors calculated with the Hydrotechnics ${ }^{\circledR}$ data processing software, HTFlow95. Since this result was highly counterintuitive, given installation in a homogeneous sand aquifer with very low water-table gradients, a detailed simulation analysis of ISPFS thermal behavior was executed (Su et al. 2005, and In Press), and the reader is referred to this work for greater detail; owing to possible complications described in the simulation study, vertical components of flow are not presented here.

Logging with the HPL and SCBFM systems took place between March 17 and March 25, 2004. A representative plot of ISPFS data from this period is shown in Figure 6. Both horizontal flow velocity and azimuth were very stable, as had been the case for these sensors. During this interval, pumping was continuous on extraction well EW-OU1-17-A (Figure 1). Azimuth values were corrected for magnetic declination, based on compass readings taken during installation of the ISPFS devices. Velocities and azimuths for the data shown in Figure 6 are shown in Table 1; means and standard deviations of direction were calculated utilizing Yamartino's method (Yamartino 1984).

Table 4.1-1. Comparison of ISPFS azimuth and horizontal flow Velocities at OU 1, March 14 to March 22, 2004

\begin{tabular}{|l|c|c|c|}
\hline Source & MW-OU1-36-A & MW-OU1-37-A & MW-OU1-39-A \\
\hline Azimuth & $312 \pm 1.4^{\circ}$ & $311 \pm 0.3^{\circ}$ & $298 \pm 1.33^{\circ}$ \\
\hline $\begin{array}{c}\text { Horizontal } \\
\text { velocity }\end{array}$ & $1.52 \mathrm{ft} /$ day & $0.107 \mathrm{ft} /$ day & $0.154 \mathrm{ft} /$ day \\
\hline
\end{tabular}

Further discussion of the response of the ISPFS sensors to changes in extraction well pumping rates can be found in Jordan et al. (2005). 


\subsection{Hydrophysical Logging}

Logging of fluid electrical conductivity (FEC) and temperature was conducted by RAS, Integrated Subsurface Evaluation, Inc., in monitoring well MW-OU1-39-A on March 23, 2004, and well MW-OU1-36-A on March 24 and March 25, 2004. Although an attempt to introduce the HPL tool into MW-OU1-37-A was made on March 24, a bend in the casing approximately 20 feet below the ground surface prevented entry.

Details of the lithology and construction of the combined ISPFS/monitoring wells installed in 1999 can be found in Oldenburg (2002). Monitoring well MW-OU1-36-A is a two inch diameter, pvc cased well with a screen from 51 to $81 \mathrm{ftbgs}$. Groundwater was reached at 63.42 feet below ground surface prior to an initial "ambient" HPL scan to establish background conductivity and temperature conditions, on March 24, 2004. Emplacement of deionized water took place the following morning, in the same manner described in Wilson et al. (2001). The HPL tool was calibrated with salt solutions prior to insertion in the well (Figure 4), placed just below the water suface, then $20 \mu \mathrm{S} / \mathrm{cm}$ water was pumped into the well with a peristaltic pump, through a tube inserted to the bottom of the well. 37 gallons of low FEC water were injected, while 35.3 were extracted, all the while monitoring the HPL conductivity readings to detect the time at which formation water had been displaced by the low FEC fluid. Subesquent logging of the well was performed at approximately hourly intervals; eight scans were completed, as shown in Figure 7.

MW-OU1-39-A is also a two inch, pvc cased monitoring well with a screened interval between 69.5 and 94.5 feet. The ambient water level prior to initial scanning was 86.70 feet below the ground surface, on March 23, 2004. Setup, tool calibration, ambient scanning, low FED fluid emplacement and logging took place on the same day, and the following morning, and was performed as described above. There were twelve postemplacement scans in all (Figure 8). Both monitoring wells exhibited reasonably uniform rates of FEC displacement over the vertical extent of logging, and the results were calculated by treating the entire borehole as a single "inflow feature." The interval specific flow rate, borehole velocities and specific discharge values for these wells are shown in Table 4.2-1.

Table 4.2-1. Hydrophysical logging estimates of flow rate, within-borehole velocity and specific discharge at OU 1, March234 to March 25, 2004

\begin{tabular}{|c|c|c|c|c|}
\hline Monitoring Well & $\begin{array}{c}\text { Depth Interval } \\
\text { (feet below ground surface) }\end{array}$ & \multicolumn{3}{|c|}{$\begin{array}{c}\text { Interval Specific Flow Rate, } \\
\text { Velocity and Specific } \\
\text { Discharge for Ambient } \\
\text { Conditions. }\end{array}$} \\
\hline & & $\mathrm{q}$ & $v^{*}$ & $\mathrm{Sd}$ \\
$(\mathrm{gpm})$ & $(\mathrm{ft} / \mathrm{day})$ & $(\mathrm{ft} / \mathrm{day})$ \\
\hline MW-OU1-36-A & $64-78$ & 0.001 & 0.22 & 0.10 \\
\hline MW-OU1-39-A & $87-97$ & 0.001 & 0.21 & 0.08 \\
\hline
\end{tabular}




\subsection{Scanning Colloidal Borescope Flowmeter}

The LLNL Scanning Colloidal Borescope Flowmeter was used to log particle velocities in all three OU 1 monitoring wells selected for this study, and the entire vertical extent of water was scanned for each at approximately two-foot intervals. MW-36-A was scanned on March 17, 2004 at seven depths, from $62.37 \mathrm{ft}$ to 71.37 feet. MW-OU1-37-A was scanned on March 20 and 21, 2004, at fourteen depths, and MW-OU1-39-A was scanned on March 22, 2004, at five depths. In each case the SCBFM magnetometer reading was checked against a compass prior to insertion into the well, the tool was lowered to the desired depth, which was detected from permanent marks on its supporting cable, and clamped to the pvc casing to allow the groundwater flow to equilibrate. The video signal could be monitored in a trailer at the wellhead; recording generally commenced within 10 minutes of reaching a new position.

Particle transport was observed on the video monitor, and recorded on standard VHS tape for later processing. The particle tracking code used was a Beta-test version of DOSbased software developed by John Wilson (at the time with Oak Ridge National Laboratory). In general, numerous particles were visible in recordings from the OU 1 wells, and the average values for their velocities and directions were averaged by the tracking software to contribute to each data point used for subsequent plotting and data reduction. The average numbers of particles tracked per point for each depth are given in Tables 4.3-1, 4.3-2, and 4.3-3, along with with the calculated average particle velocity and azimuth. Reported azimuth values were corrected for magnetic declination. In order to minimize errors in calculating average azimuth, owing to data clustered around true north, a spreadsheet formulation implementing the Yamartino algorithm (originally developed for calculating average wind direction and standard deviation) was used (Yamartino 1984).

Table 4.3-1. SCBFM logging estimates of within borehole groundwater velocity and direction from MW-OU1-36-A, collected on March 17, 2004.

\begin{tabular}{|c|c|c|c|c|}
\hline Depth (ftbgs) & $\begin{array}{c}\text { Average \# of } \\
\text { particles tracked }\end{array}$ & $\begin{array}{c}\text { Velocity } \\
(\mathrm{ft} / \text { day })^{1}\end{array}$ & $\begin{array}{c}\text { Azimuth } \\
\left({ }^{\circ} \pm \text { S.D. }\right)^{2}\end{array}$ & Remarks \\
\hline 62.37 & 35 & - & - & Variable flow and direction \\
\hline 63.87 & 46 & - & - & Variable flow and direction \\
\hline 65.37 & 43 & 5.5 & $190 \pm 56.5$ & Stable flow \\
\hline 66.87 & 39 & - & - & Variable flow and direction \\
\hline 68.37 & 60 & 3.0 & $4.8 \pm 23.0$ & Stable flow \\
\hline 69.87 & 60 & 3.1 & $83.8 \pm 23.6$ & Stable flow \\
\hline 71.37 & 36 & 3.3 & $310 \pm 58.2$ & Stable flow \\
\hline
\end{tabular}

${ }^{1}$ Arithmetic means for the number of particles tracked, per point, for entire scan

${ }^{2}$ Calculated as per Yamartino (1984). 
Table 4.3-2. SCBFM logging estimates of within borehole groundwater velocity and direction from MW-OU1-37-A, collected on March 20 and March 21, 2004.

\begin{tabular}{|c|c|c|c|c|}
\hline Depth (ftbgs) & $\begin{array}{c}\text { Average \# of } \\
\text { particles tracked }\end{array}$ & $\begin{array}{l}\text { Velocity } \\
(\mathrm{ft} / \text { day })^{1}\end{array}$ & $\begin{array}{l}\text { Azimuth } \\
\left({ }^{\circ} \pm \text { S.D. }\right)^{2}\end{array}$ & Remarks \\
\hline 62.92 & 35 & 7.0 & $144 \pm 23.9$ & Stable flow \\
\hline 64.42 & 35 & - & - & Stable flow, unstable direction \\
\hline 65.92 & 38 & 6.5 & $93.5 \pm 32.0$ & Stable flow \\
\hline 67.42 & 26 & 7.5 & $91.4 \pm 11.0$ & Stable flow \\
\hline 68.92 & 47 & 8.0 & $282 \pm 33.2$ & Stable flow \\
\hline 70.42 & 30 & 16.3 & $208 \pm 17.5$ & Stable flow \\
\hline 71.92 & 19 & 11.3 & $130 \pm 22.3$ & Stable flow \\
\hline 73.42 & 52 & 10.4 & $173 \pm 7.4$ & Stable flow \\
\hline 74.92 & 44 & 22.7 & $139 \pm 3.3$ & Stable flow \\
\hline 76.42 & 28 & 11.3 & $103 \pm 10.4$ & Stable flow \\
\hline 77.92 & 44 & 22.7 & $139 \pm 5.2$ & Stable flow \\
\hline 79.42 & 27 & 13.7 & $148 \pm 6.7$ & Stable flow \\
\hline 80.92 & 32 & 9.6 & $112 \pm 5.0$ & Stable flow \\
\hline 82.42 & 32 & 10.2 & $162 \pm 8.8$ & Stable flow \\
\hline
\end{tabular}

${ }^{1}$ Arithmetic means for the number of particles tracked, per point, for entire scan

${ }^{2}$ Calculated as per Yamartino (1984).

Table 4.3-1. SCBFM logging estimates of within borehole groundwater velocity and direction from MW-OU1-36-A, collected on March 17, 2004.

\begin{tabular}{|c|c|c|c|c|}
\hline Depth (ftbgs) & $\begin{array}{c}\text { Average \# of } \\
\text { particles tracked }\end{array}$ & $\begin{array}{c}\text { Velocity } \\
(\mathrm{ft} / \text { day })\end{array}$ & $\begin{array}{c}\text { Azimuth } \\
\left({ }^{\circ} \pm \text { S.D. }\right)^{2}\end{array}$ & Remarks \\
\hline 86.01 & 45 & - & - & Variable flow and direction \\
\hline 87.51 & 27 & 5.64 & $41.9 \pm 8.3$ & Stable flow \\
\hline 88.01 & 48 & 18.8 & $27.6 \pm 10.0$ & Stable flow \\
\hline 89.51 & 52 & 11.0 & $27.4 \pm 6.1$ & Stable flow \\
\hline 91.01 & 60 & 8.2 & $25.2 \pm 31.6$ & Stable flow \\
\hline
\end{tabular}

${ }^{1}$ Arithmetic means for the number of particles tracked, per point, for entire scan

${ }^{2}$ Calculated as per Yamartino (1984). 


\section{CONCLUSIONS}

Each of the flow sensing systems has unique attributes that will help determine appropriate field applications. The ISPFS probes are permanently installed and nonretrievable, whereas the HPL and SCBFM systems are lightweight devices with modest support equipment, that are amenable to field mobilization by one or two workers. The ISPFS is therefore designed for long-term recording of flow responses with essentially no maintenance, following initial installation, while the other two tools are deployed to collect point estimates of flow parameters.

The ISPFS data from this site are the subject of a detailed comparison with OU 1 aquifer response data, and appear to have provided flow rate data that correlate well with estimates based on formation conductivity estimates, from short-term pump tests and long-term extraction, and gradient analysis (Jordan et al. 2005). The ISPFS data selected for comparison with the other flow monitoring tools in this report are in generally good agreement with the trends of both azimuth and horizontal velocity illustrated in that report, for the period between 2001 and 2003, although the inverted ISPFS horizontal velocity for MW-OU1-36-A during March 2004 was substantially higher than that recorded earlier, for unknown reasons.

The RAS HPL logging system, while incapable of producing azimuth estimates, produced borehole velocity estimates for the two wells examined that were in good agreement with the corresponding ISPFS data. In keeping with the approach used by Wilson et al. (2001) for logging studies in Midwestern karst formations, the data presented here were not corrected for presumed acceleration of flow field patterns in or around the borehole.

We note that the two wells logged here had quite different vertical profiles of FEC recovery following emplacement of the low FEC fluid: while MW-OU1-39-A FEC recovered very evenly across the vertical extent of the well, MW-OU1-36-A appeared to have a significant gradient of higher displacement rate with increasing depth. Although the vertical logs were treated as single "inflow features" for the present analysis, it may be possible to subdivide the data and attempt further analysis of differential vertical flow distributions, even in wells installed in apparently homogeneous aquifers such as the one investigated here.

For this analysis, the LLNL scanning borescope data were reported without correction for borehole-induced acceleration effects. Even if these were applied (division by factors of from 2 to 4, or more), the flow velocity measurements reported would still be greater than the estimates from the other two tools, although in this case the magnitude of differences is much lower than those observed in other studies, particularly Wilson et al. (2001): the SCBFM data (if divided by 4), are from 1.3 to 5.6 times the values estimated by the HPL, and for MW-OU1-37-A and MW-OU1-39-A, about twice as great again as the ISPFS estimates. Owing to the rather anomalously high ISPFS values during this period for MW-OU1-36-A, the borescope velocity estimates agree closely with the ISPFS data, but this degree of agreement is suspicious.

Moreover, the direction data from the SCBFM system do not correspond at all with the ISPFS data. While this level of disagreement has been observed in more challenging hydrogeological settings (Wilson et al. 2001), where flow in fractured bedrock surely 
created highly complex flow patterns, it is difficult to understand in the present setiing, in what has been assumed to be a highly homogeneous, nearly graded sand aquifer at OU 1 . Perhaps sampling with this tool for more extended periods, during extraction well shutdown and startup, might shed more light on this seeming disparity.

\section{Summary}

Three groundwater flow sensing systems were deployed in the spring of 2004 at the source area of a TCE plume at the Operable Unit 1 of the former Fort Ord Army Base, Monterey County, California. The three systems employ entirely different modes of operation, but all three produce estimates of groundwater flow rate, and two produce estimates of the direction of groundwater flow. The Hydrotechnics ${ }^{\circledR}$ ISPFS system is a permanently installed device that utilizes high precision temperature sensing over the surface of a heated cylindrical probe to measure heat displaced by groundwater flow. Inversion algorithms produce estimates of both horizontal and vertical flow vectors, as well as an azimuth for groundwater flow direction. The device is buried directly in the formation without casing or sandpack, and appears to produce data that are in good agreement with standard analysis of aquifer conductivity generated by pumping tests, combined with gradient analysis. It is designed to provide long-term logging of flow parameters with essentially no operator intervention or maintenance.

The other two tools examined are designed to vertically scan through the water standing in the borehole, and log data that can be used to calculate flow rates, and in one case, flow direction. The RAS HPL system utilizes displacement of groundwater from the well by introduced low electrical conductivity water. As horizontal flow of formation water pushes this low conductivity "tracer" from the well, continuous vertical recordings of conductivity recovery are made, from which influx rates are calculated. The equipment is highly portable; in the present case one well was logged with this system on each day. While not producing flow direction data, this system produced estimates of flow velocity that were in close agreement with the ISPFS data, without addition of any correction for presumed acceleration of groundwater velocity induced by the borehole itself.

The last tool examined, the LLNL scanning colloidal borescope, is also a portable logging tool that can be operated readily by a single worker, logging at a rate roughly equal to that of the RAS HPL system. Its operating principle is the video recording of back-lit particles by a down-hole CCD camera, illuminated from below by a highintensity lamp. Computer software digitizes the video recordings, detects and identifies particles between adjacent image "frames," and calculates horizontal displacement and direction. Many particles are monitored for each data record, that can then be reduced for plotting or statistical analysis. In this study SCBFM data tended to over-report borehole velocities when compared with the other two tools, but the disagreement was not as great as reported in other comparative efforts. However, flow direction did not correlate with data produced by the ISPFS, even though the experiment was performed in what has heretofore been considered a nearly ideal, homogeneous sand aquifer. The reasons for this disparity are not understood at this time. Further detailed experimentation with this device is surely warranted, as its speed of deployment and reasonable agreement with the overall magnitude of flow velocities generated by the other two tools appear to be positive results. 


\section{REFERENCES}

Ballard, S., 1996. The in situ permeable flow sensor: A ground-water flow velocity meter. Ground Water 34: 231-240.

Ballard, S., G.T. Barker, and R.L. Nichols, 1996. A test of the in situ permeable flow sensor at Savannah River, SC. Ground Water 34: 389-396.

Cohen, A.J.B., 1995. Hydrogeologic characterization of fractured rock formations-A guide for groundwater remediators. Lawrence Berkeley National Laboratory Report LBL-38142/UC-800, 144 pp.

Drost, W., D. Klotz, A. Koch, H. Moser, F. Neumaier, and W. Rauert, 1968. Water Resources Res. 4: 125-146.

Foster, J.W. and L.J. Fryda, 1990. Ground water azimuth detection. U.S. Patent $\# 4,963019$.

Hess, A.E., 1986. Identifying hydraulically conductive fractures with a slow-velocity borehold flowmeter. Can. Geotech. J. 23: 69-78.

Jordan, P.D., C.M. Oldenburg, and G.W. Su, 2005. Analysis of aquifer response, groundwater flow, and plume evolution at Site OU 1, former Fort Ord, California. Lawrence Berkeley National Laboratory Report LBNL-57251.

Kearl, P.M., 1997. Obervations of particle movement in a monitoring well using the colloidal borescope. J. Hydrology 200: 323-344.

Kearl, P.M. and C.M. Case, 1992. Direct field measurement of groundwater velocities. Interdisciplinary Approaches in Hydrology and Hydrogeology, American Institute of Hydrology, pp. 91-102.

Kearl, P.M., N.E. Korte, and T.A. Cronk, 1992. Suggested modifications to groundwater sampling procedures based on observations from the colloidal borescope. Groundwater Monitoring Rev. 12: 155-161.

Kearl, P.M. and K. Roemer, 1998. Evaluation of groundwater flow in a heterogeneous aquifer using the colloidal borescope. Advances in Environmental Research 3: 49-57.

Kerfoot, W.B., 1988. Monitoring well construction, and recommended procedures for direct ground-water flow measurements using a heat-pulsing flowmeter, in Ground water contamination-Field methods. ASTM Special Technical Publication 963, American Society for Testing and Materials, Philadelphia, PA, 
pp 146-161.

Kerfoot, W.B., 1995. Independent verification of heatpulse groundwater flowmeter results through long term observation and tracer tests on Superfund sites. in Hydrocarbon Contaminated Soils, v. V, Amherst Scientific Publishers, Amherst, MA, pp 37-49.

Molz, F.J., R.H. Morin, A.E. Hess, J.G. Melville, and O. Guven, 1989. The impeller meter for measuring aquifer permeability variations - Evaluation and comparison with other tests. Waer Resources Res. 25: 1677-1683.

Momii, K., K. Jinno, and F. Hirano, 1993. Laboratory studies on a new laser Doppler velocimeter system for hirizontal groundwater velocity measurements in a borehole. Water Resources Res. 29: 283-291.

Oldenburg, C. M., P. F. Daley, B. M. Freifeld, J. Hinds, and P. D. Jordan, 2002. ThreeDimensional Groundwater Flow, Aquifer Response, and Treatment System Monitoring at Site OU 1, Fort Ord, California, Lawrence Berkeley National Laboratory Report, $L B N L-49586$, Lawrence Berkeley National Laboratory, February.

Pedler, W.H., R.E. Crowder, J.M. Seracuse, N.J. Myers, J. Daniel, and L. Haines, 1995. Vertical profiling of aquifer flow characteristics and water quality parameters using hydrophysical logging ${ }^{\mathrm{TM}}$. In Proceedings of the Symposium on the Application of Geophysics to engineering and Environmental Problems, April 2326, Environmental and Engineering Geophysical Society, Orlando, FL pp. 311318.

Pedler, W.H. and D.W. Urish, 1988. Detection and characterization of hydraulically conductive fractures in a borehole - the emplacement method. EOS, Transactions of the American Geophysical Union v. 69, no. 44, pp.1, 186.

SonTek, Inc., 1996. Modified ADV for 3D velocity measurements in boreholes -Final project report. U.S. Geological Survey Contract Number 1434-95-C-40232, 29 pp.

Su, G.W., B.M. Freifeld, C.M. Oldenburg, P.D. Jordan, and P.F. Daley, 2005. Data analysis and simulation of in-situ permeable flow sensors for measuring groundwater velocity, Lawrence Berkeley National Laboratory Report, $L B N L$ 57084, and Groundwater, in Press.

Tsang, C.F., P. Hufschmied, and F.V. Hale, 1990. Determination of fracture inflow parameters with a a borehole fluid conductivity logging method. Water Resources Res. 26: 561-578. 
Wilson, J.T., W.A. Mandell, F.L. Paillet, E.R. Bayless, R.T. Hanson, P.M. Kearl, W.B. Kerfoot, M.W. Newhouse, and W.H. Pedler, 2001. An evaluation of borehole flowmeters used to measure horizontal ground-water flow in limestones of Indiana, Kentucky, and Tennessee, 1999. USGS Water-Resources Investigations Report 01-4139.

Yamartino, R.J., 1984. A comparison of several "single-pass" estimators of the standard deviation of wind direction. J. Climate Appl. Meteorol. 23: 1362-1366.

Young, S.C., H.S. Pearson, G.K. Moore, and R.B. Clapp, 1991. Application of the electromagnetic borehole flowmeter technique at the Oak Ridge Laboratory. Tennessee Valley Authority Report WR28-1-900-247, Norris, Tenn. 


\section{LIST OF FIGURES}

Figure 1. Fort Ord Operable Unit, Fire Drill Area (OU 1-FDA).

Figure 2. Schematic of an ISPFS and adjacent monitoring well at OU 1.

Figure 3. Installation of ISPFS with hollow-stem auger.

Figure 4. Calibration of the HPL tool.

Figure 5. Preparing to install the Scanning Colloidal Borescope Flow Meter.

Figure 6. Groundwater flow rates and azimuth estimates derived from the ISPFS.

Figure 7. HPL depth profiles of FEC and temperature from MW-OU1-36-A.

Figure 8. HPL depth profiles of FEC and temperature from MW-OU1-39-A.

Figure 9. SCBFM flow rates and azimuth estimates for MW-OU1-36-A, depths 1-3.

Figure 10. SCBFM flow rates and azimuth estimates for MW-OU1-36-A, depths 4-6.

Figure 11. SCBFM flow rates and azimuth estimates for MW-OU1-36-A, depth 7.

Figure 12. SCBFM flow rates and azimuth estimates for MW-OU1-37-A, depths 1-3.

Figure 13. SCBFM flow rates and azimuth estimates for MW-OU1-37-A, depths 4-6.

Figure 14. SCBFM flow rates and azimuth estimates for MW-OU1-37-A, depths 7-9.

Figure 15. SCBFM flow rates and azimuth estimates for MW-OU1-37-A, depths 10-12.

Figure 16. SCBFM flow rates and azimuth estimates for MW-OU1-37-A, depths 13-14.

Figure 17. SCBFM flow rates and azimuth estimates for MW-OU1-37-A, depths 1-3.

Figure 18. SCBFM flow rates and azimuth estimates for MW-OU1-37-A, depths 4-5. 


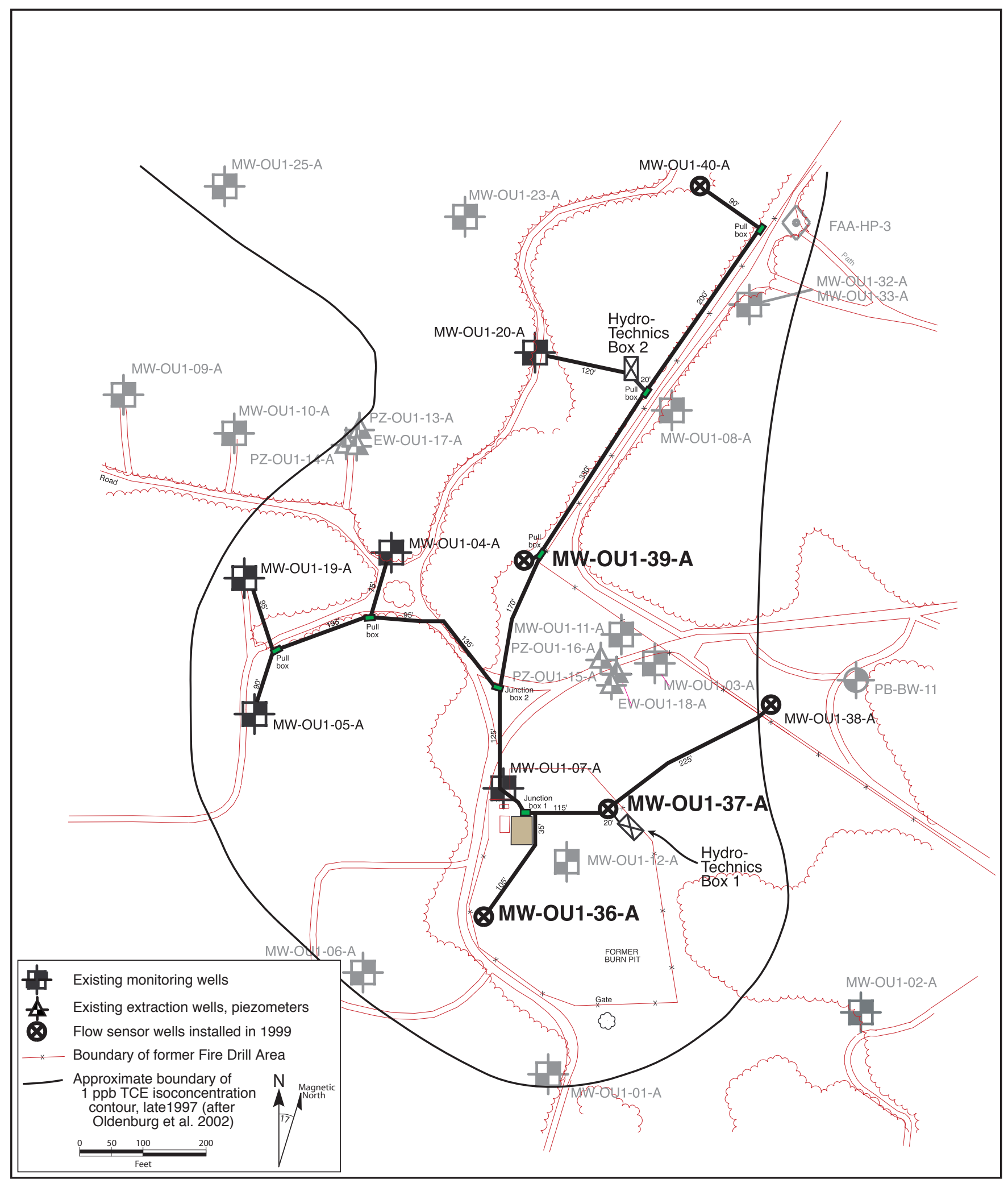

Figure 1. Fort Ord Operable Unit 1, Fire Drill Area (OU 1-FDA). Geochemical analysis instruments and logging computers used with the Hydrotechnics ${ }^{\circledR}$ flow sensors are located in the shelter south of MW-OU1-07-A. Wells instrumented for the flow monitoring comparison are labeled in boldface (MW-OU1-36-A, MW-OU1-37-A, and MW-OU1-39-A). 


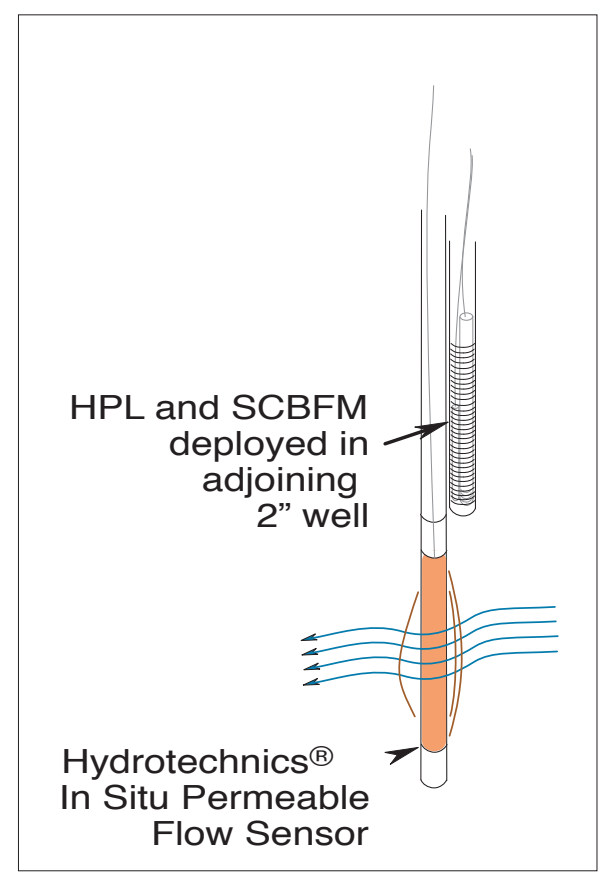

Figure 2. Schematic of ISPFS and adjacent monitoring well installation.

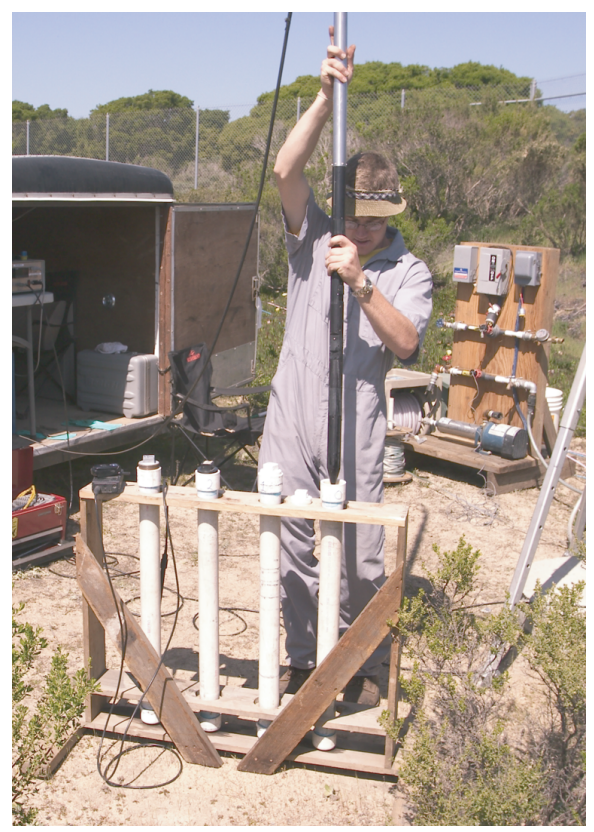

Figure 4. Calibration of the Hydrophysical logging tool with standardized salt solutions.

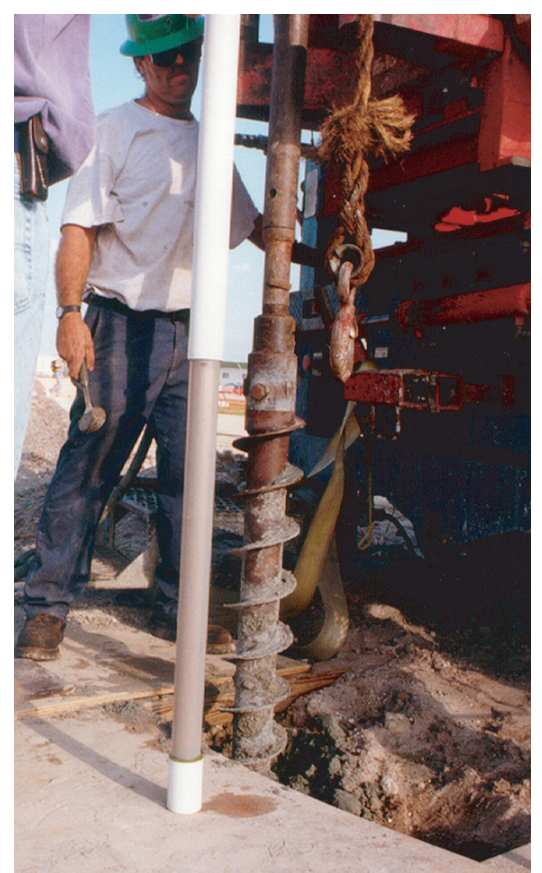

Figure 3. Installation of an ISPFS with a hollow-stem auger at OU1.

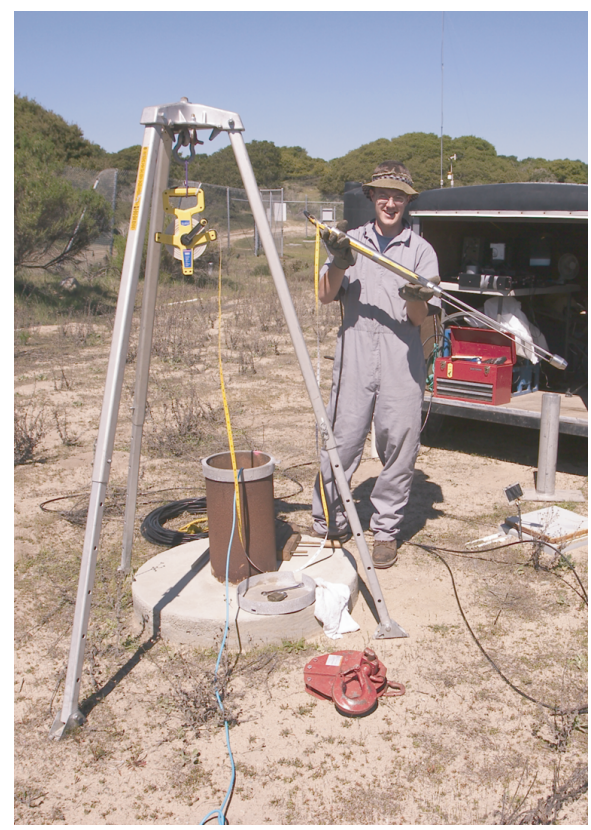

Figure 5. Preparing for installation of the LLNL Scanning Colloidal Borescope Flow Meter 

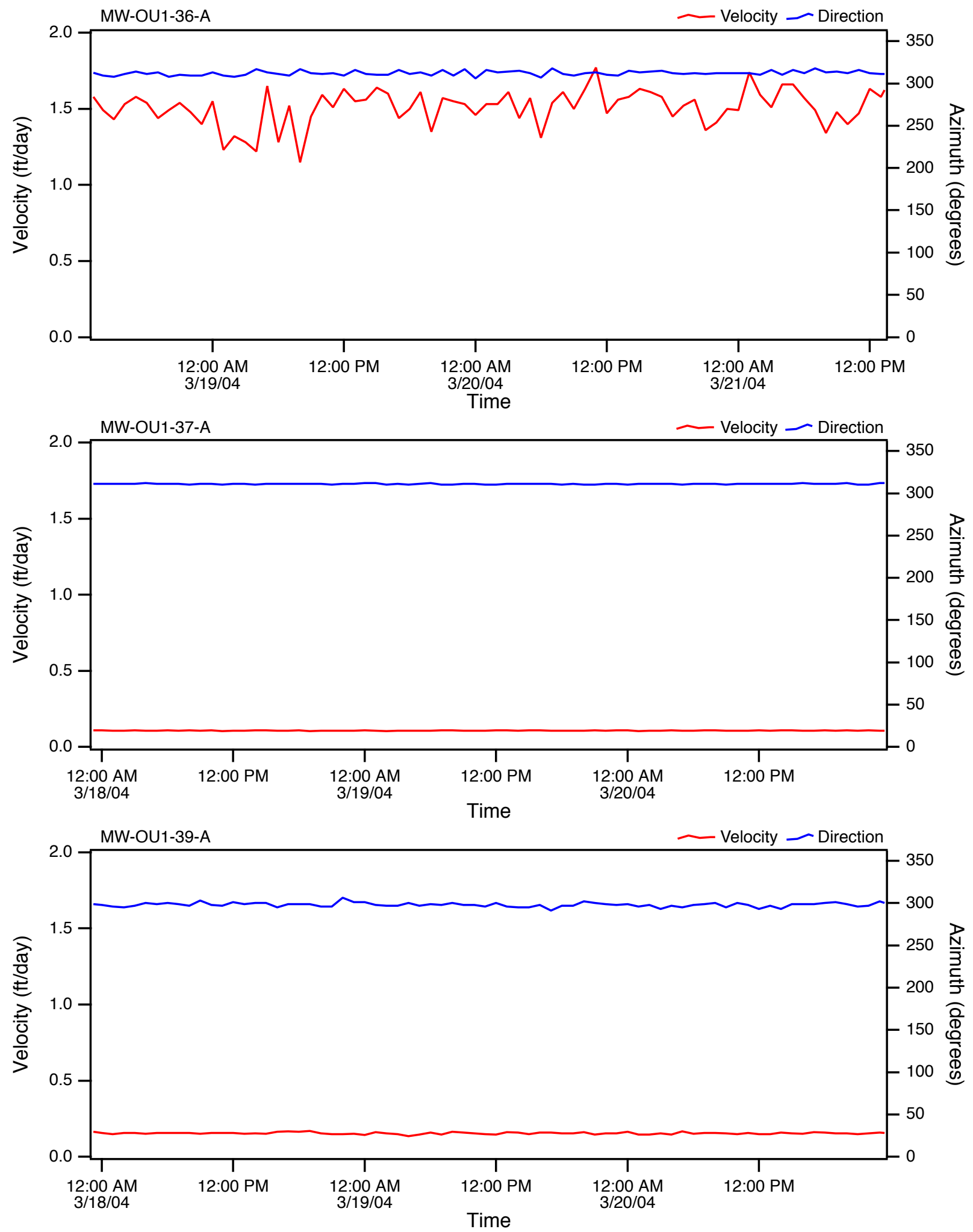

Figure 6. Groundwater flow rates and azimuth estimates derived from ISPFS logging. Data derived from inversion of raw thermistor data with HTFlow95. 


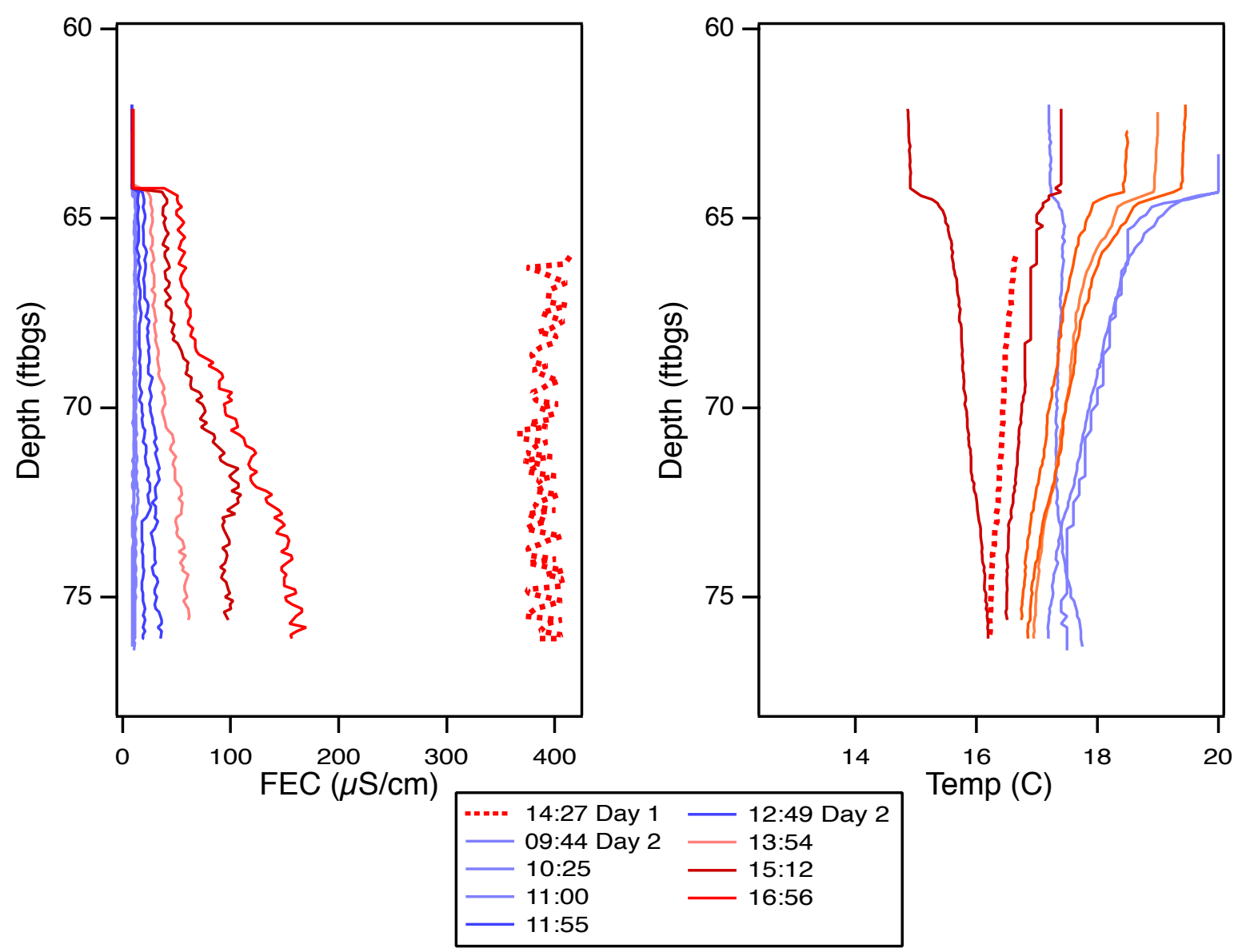

Figure 7. Hydrophysical logging data from MW-OU1-36A, March 25, 2004: depth profile of electrical conductivity (a.) and fluid temperature (b.) following an initial scan of ambient conditions (dotted lines), replacement of borehole fluid with deionized water, and reinfiltration with formation water. 


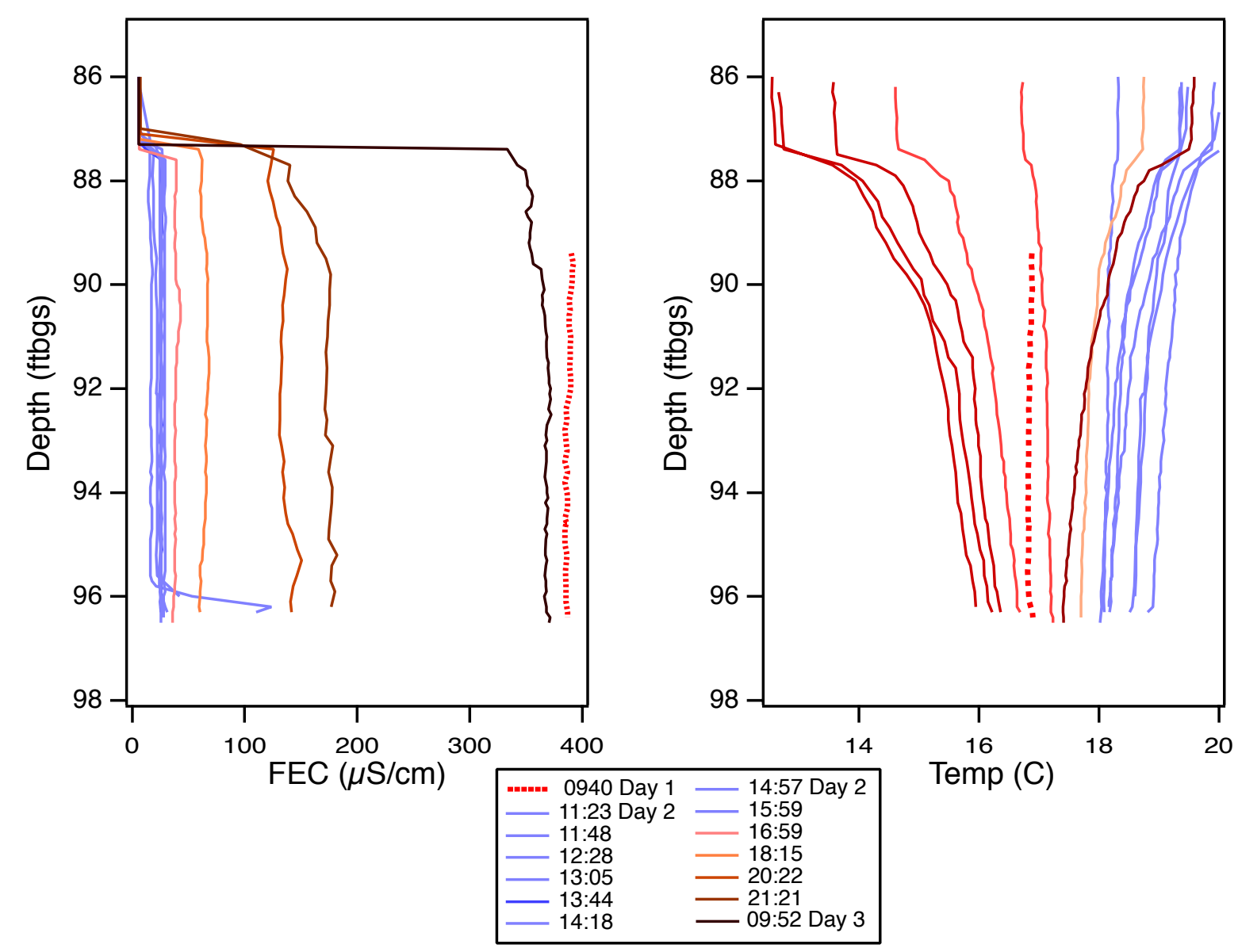

Figure 8. Hydrophysical logging data from MW-OU1-39A, March 23, 2004: depth profile of electrical conductivity (a.) and fluid temperature (b.) following an initial scan of ambient conditions (dotted lines), replacement of borehole fluid with deionized water, and reinfiltration with formation water. 

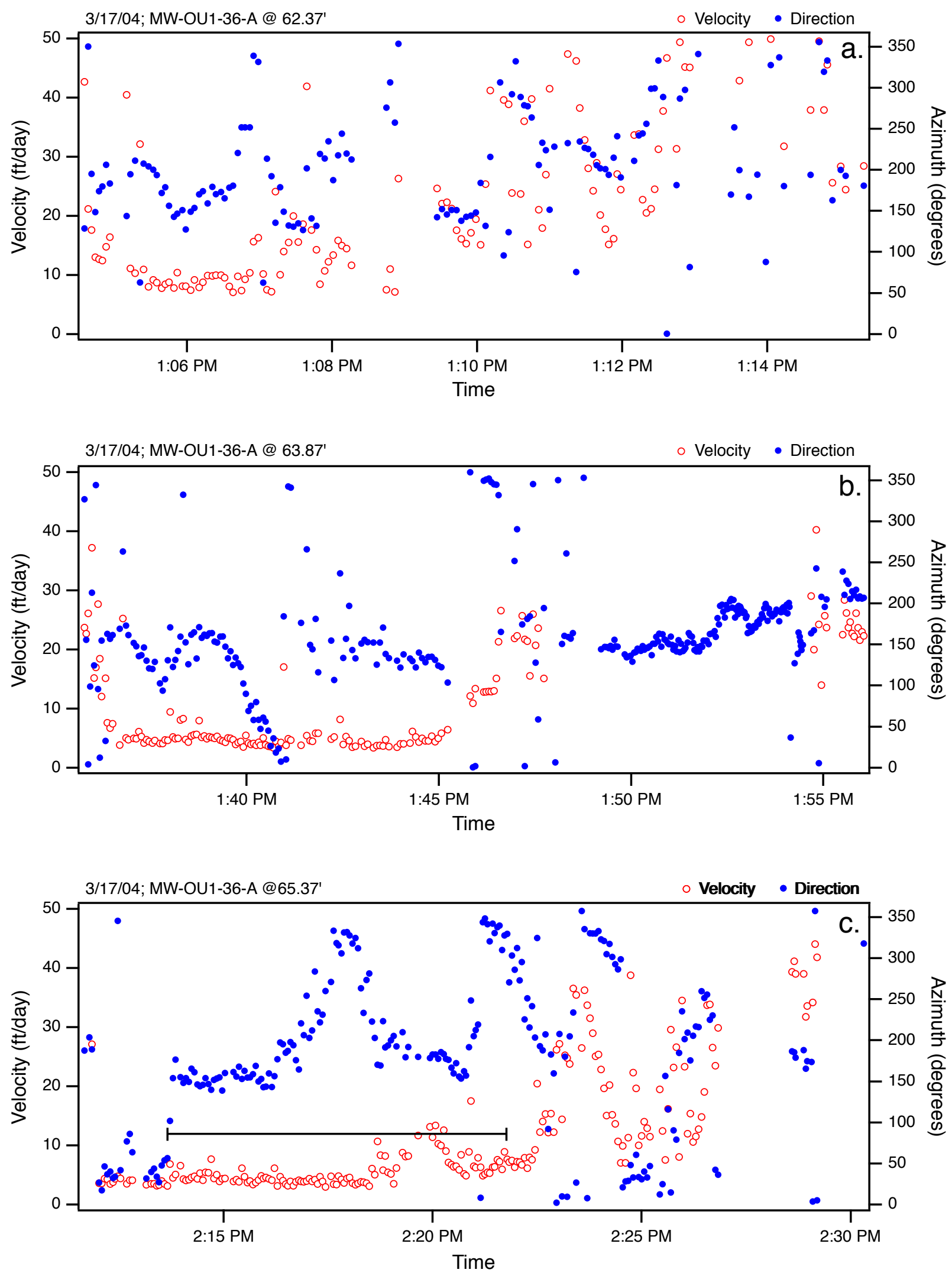

Figure 9. Groundwater flow rates and azimuth estimates derived from SCBFM image analysis. Horizontal bars indicate regions of stable particle flow rate and direction, from which numerical estimates could be made. Measurements from MW-OU1-36-A at: 62.37'(a.), 63.87' (b.), and 65.37'(c.) below the ground surface. 

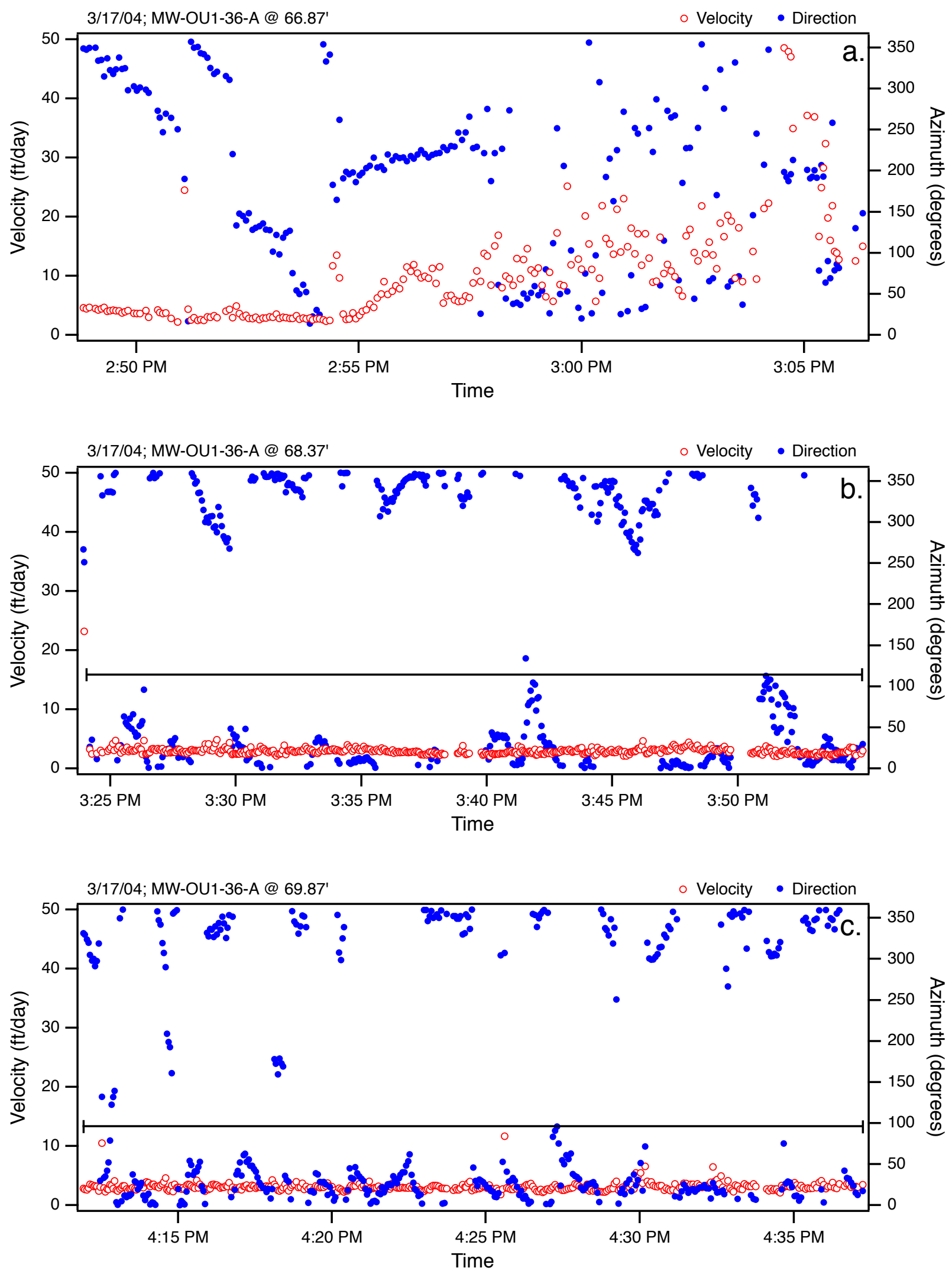

Figure 10. Groundwater flow rates and azimuth estimates derived from SCBFM image analysis. Horizontal bars indicate regions of stable particle flow rate and direction, from which numerical estimates could be made. Measurements from MW-OU1-36-A at: 66.87'(a.), 68.37'(b.), and 69.87'(c.) below the ground surface. 


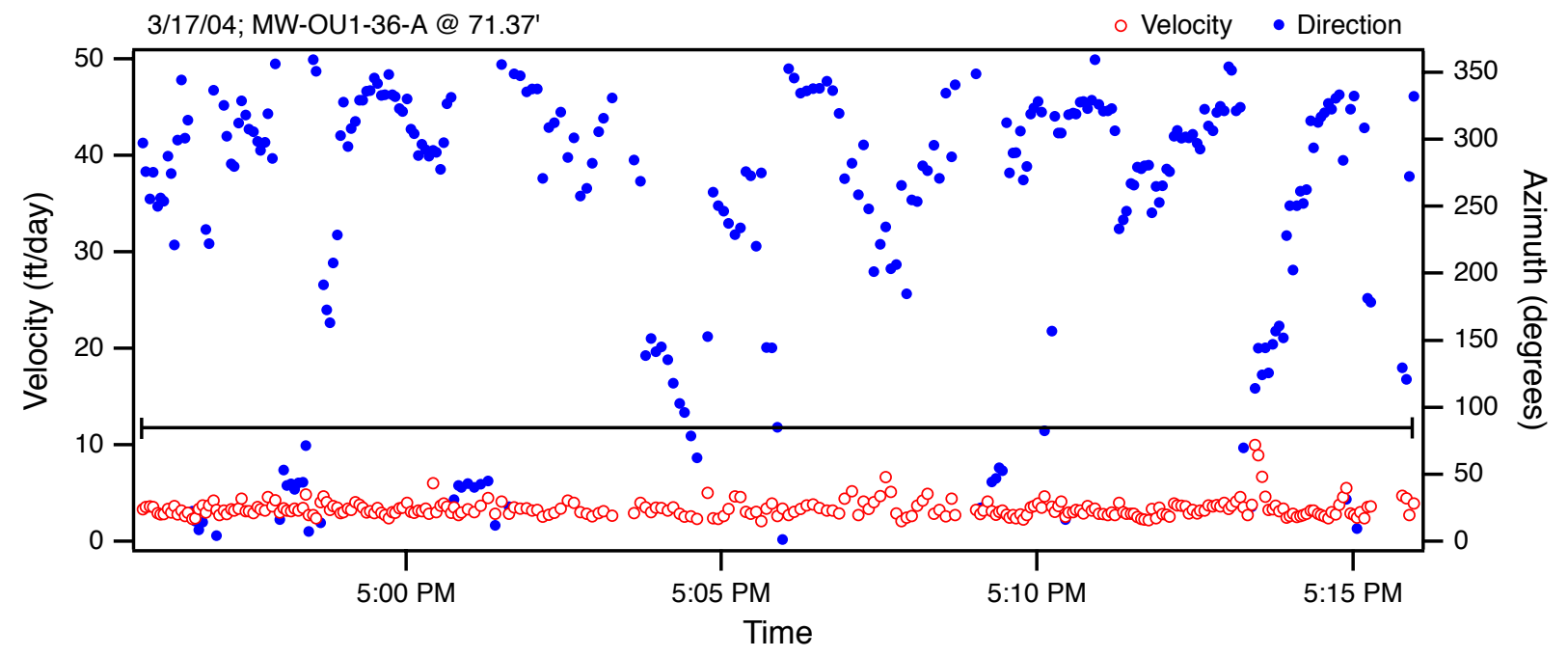

Figure 11. Groundwater flow rates and azimuth estimates derived from SCBFM image analysis. Horizontal bar indicates region of stable particle flow rate and direction, from which a numerical estimate could be made. Measurements from MW-OU1-36-A at: 71.37' below the ground surface. 

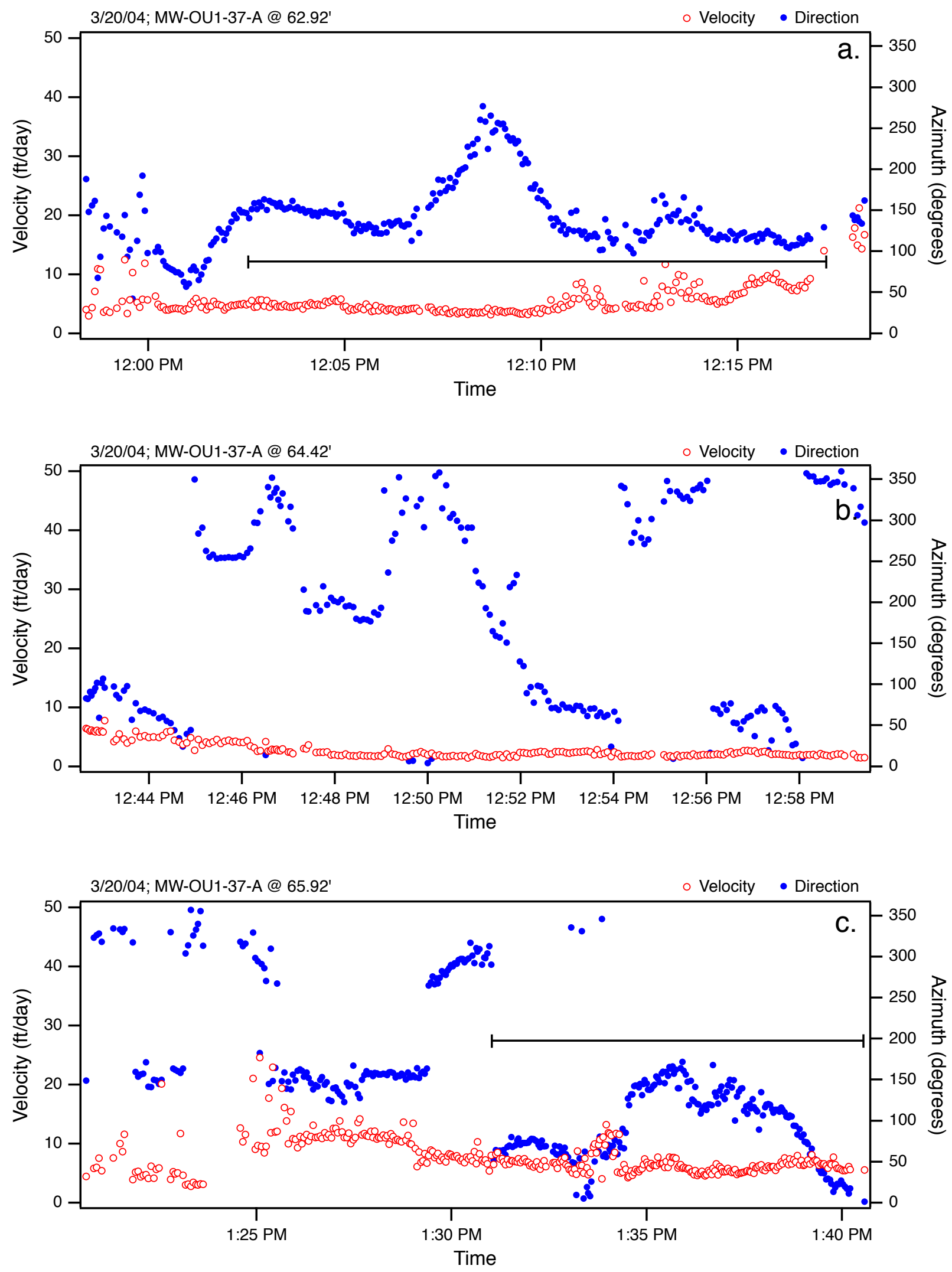

Figure 12. Groundwater flow rates and azimuth estimates derived from SCBFM image analysis. Horizontal bars indicate regions of stable particle flow rate and direction, from which numerical estimates could be made. Measurements from MW-OU1-37-A at: 62.92'(a.), 64.42'(b.), and 65.92'(c.) below the ground surface. 

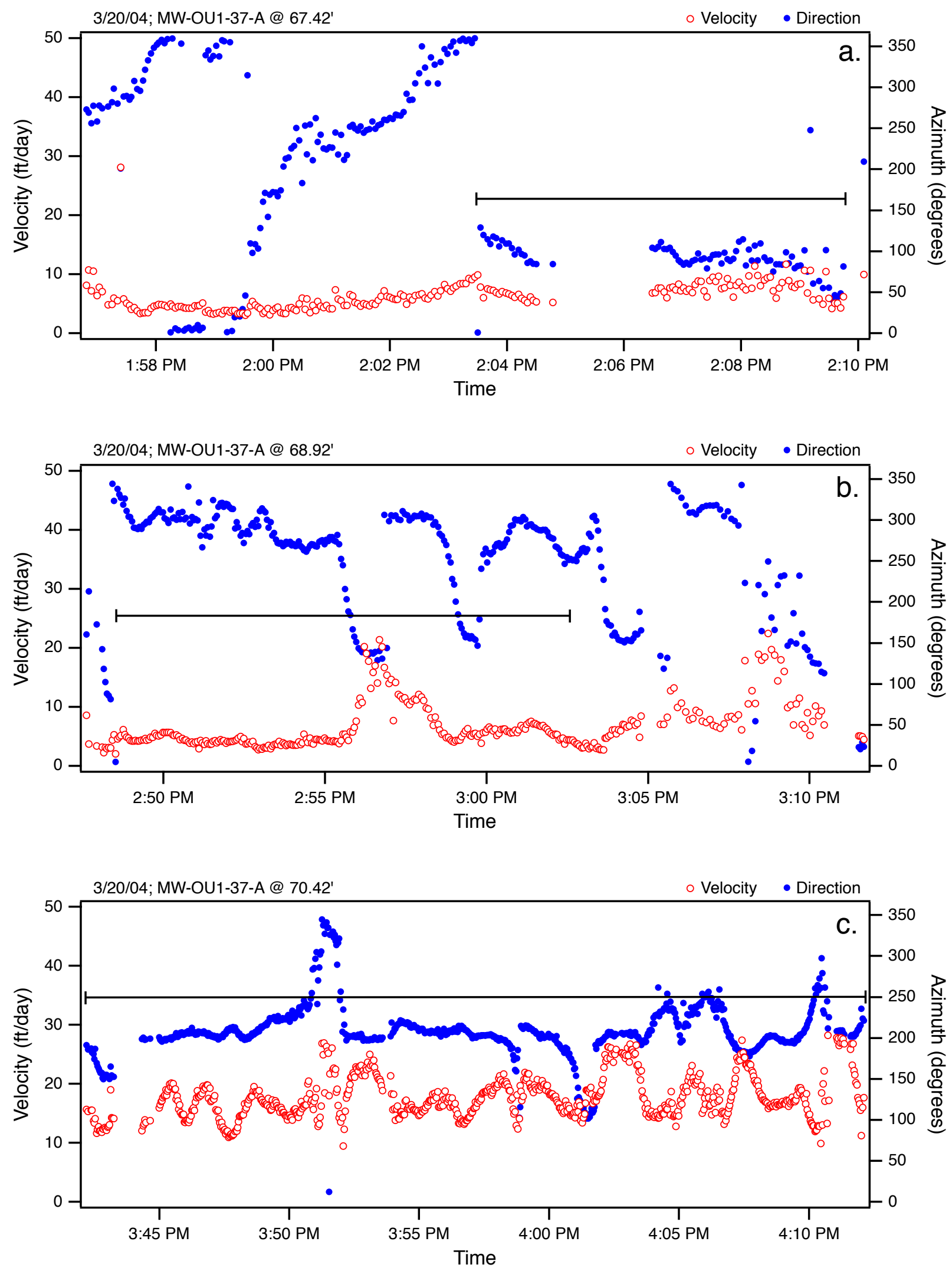

Figure 13. Groundwater flow rates and azimuth estimates derived from SCBFM image analysis. Horizontal bars indicate regions of stable particle flow rate and direction, from which numerical estimates could be made. Measurements from MW-OU1-37-A at: 67.42'(a.), 68.92'(b.), and 70.42'(c.) below the ground surface. 

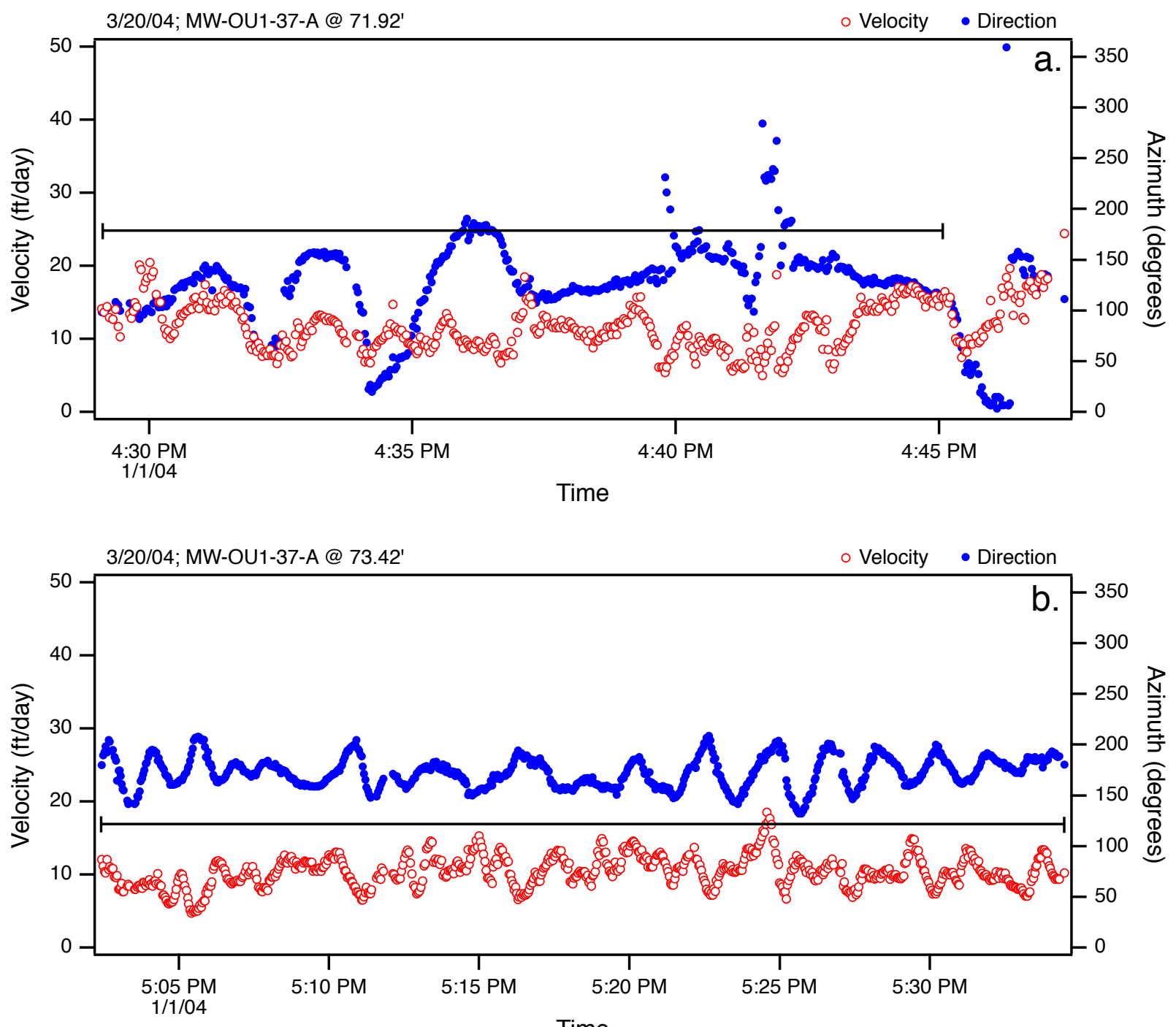

Time

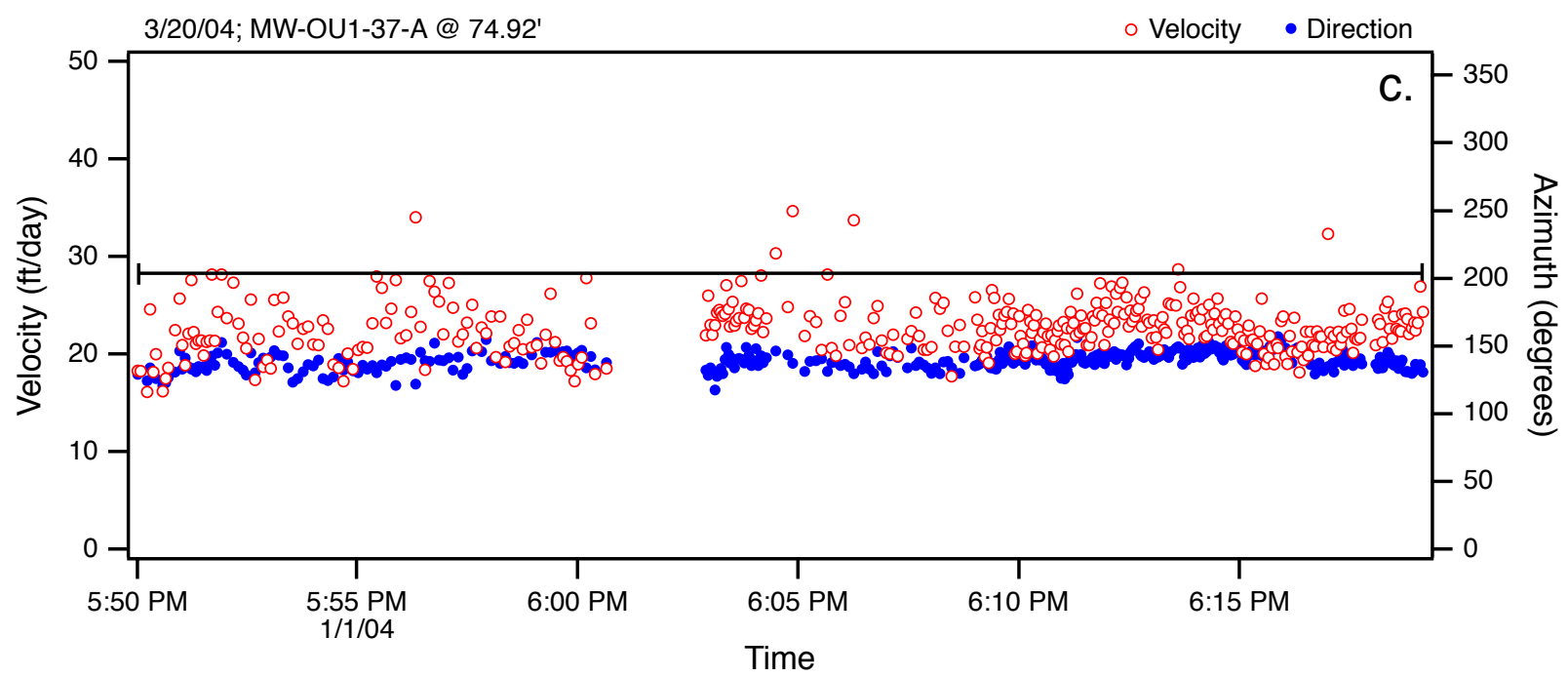

Figure 14. Groundwater flow rates and azimuth estimates derived from SCBFM image analysis. Horizontal bars indicate regions of stable particle flow rate and direction, from which numerical estimates could be made. Measurements from MW-OU1-37-A at: 71.92'(a.), 73.42' (b.), and 74.92'(c.) below the ground surface. 

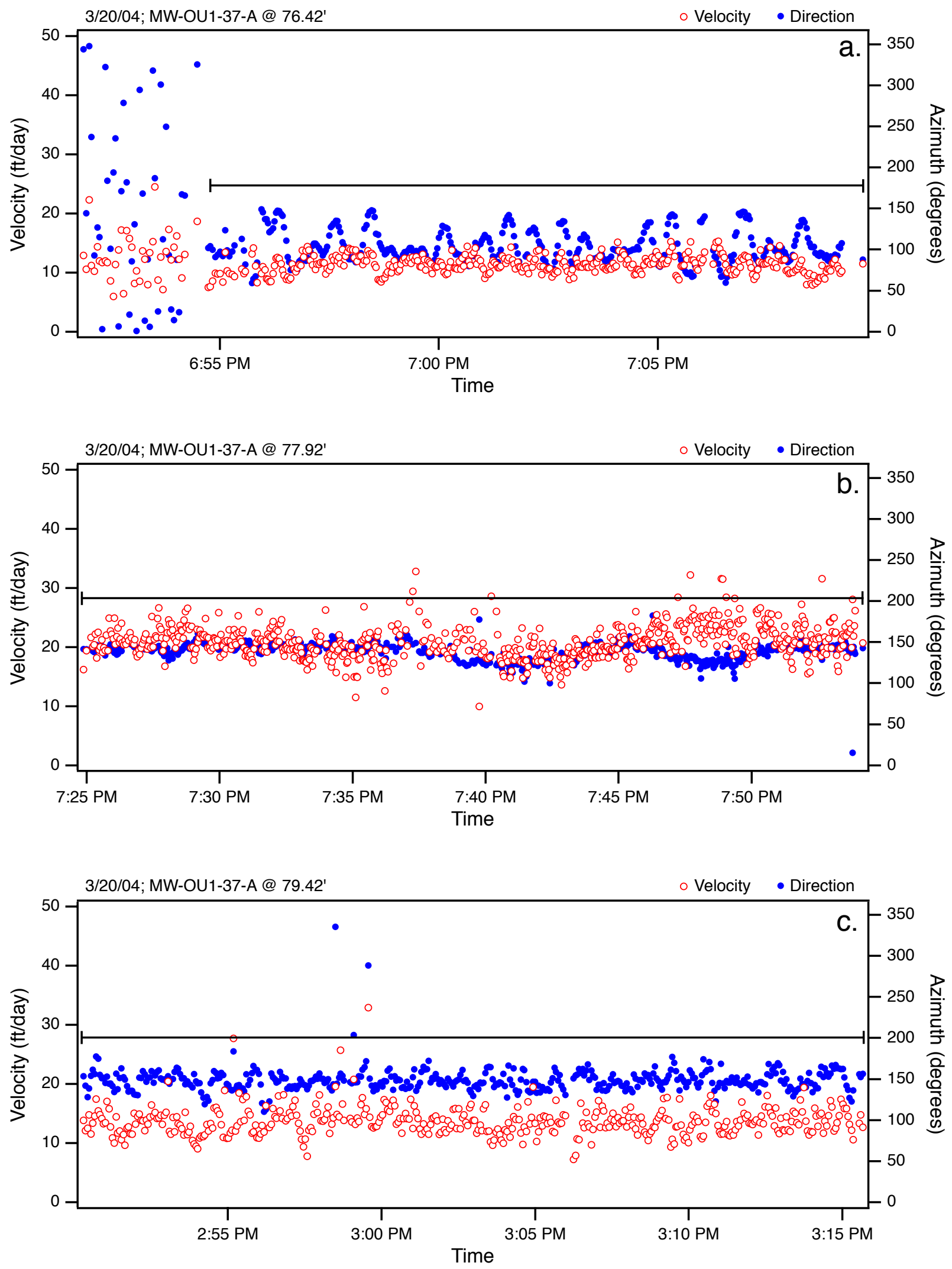

Figure 15. Groundwater flow rates and azimuth estimates derived from SCBFM image analysis. Horizontal bars indicate regions of stable particle flow rate and direction, from which numerical estimates could be made. Measurements from MW-OU1-37-A at: 76.42'(a.), 77.92'(b.), and 79.92'(c.) below the ground surface. 

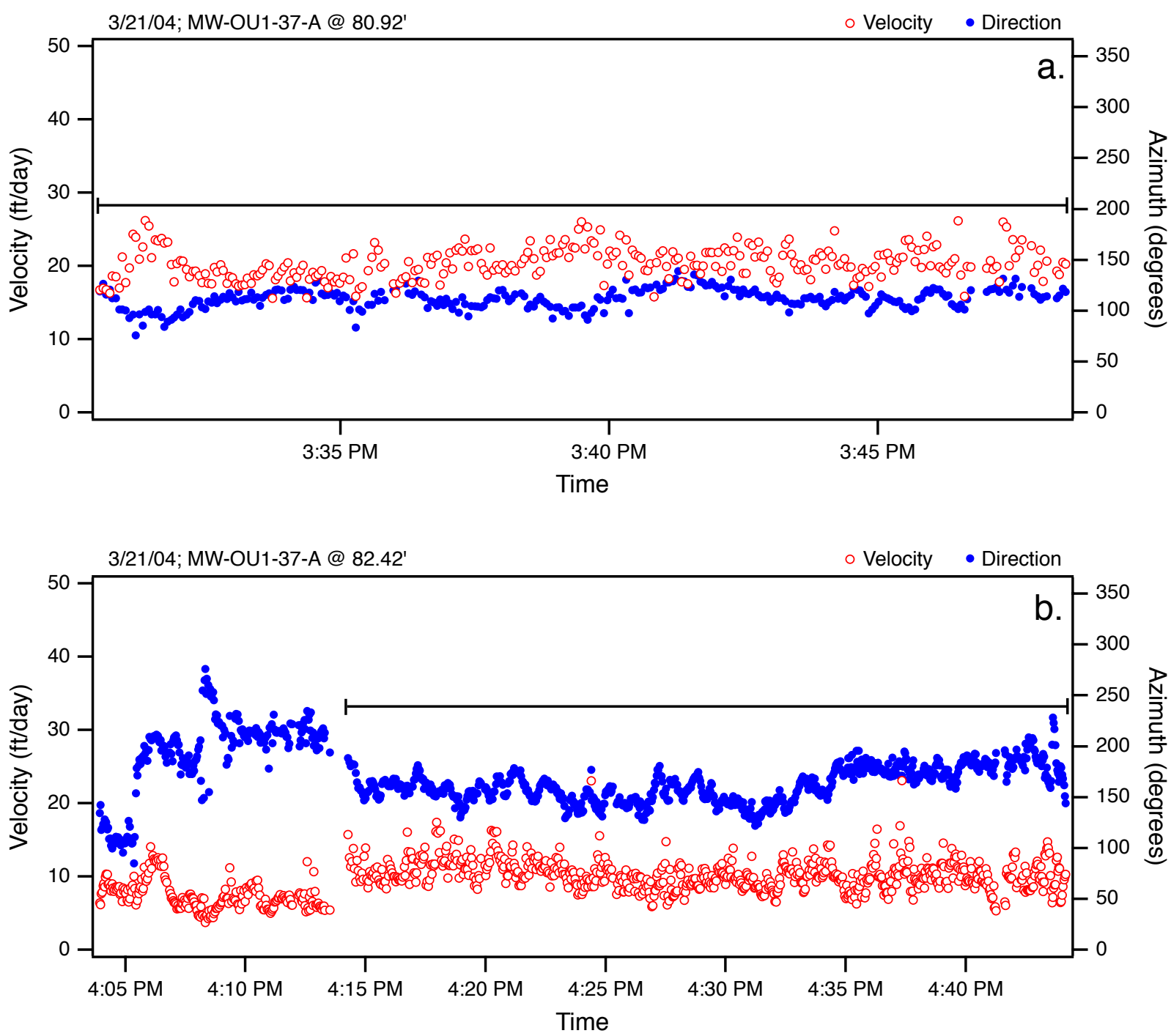

Figure 16. Groundwater flow rates and azimuth estimates derived from SCBFM image analysis. Horizontal bars indicate regions of stable particle flow rate and direction, from which numerical estimates could be made. Measurements from MW-OU1-37-A at: 80.92' (a.) and 82.42'(b.) below the ground surface. 

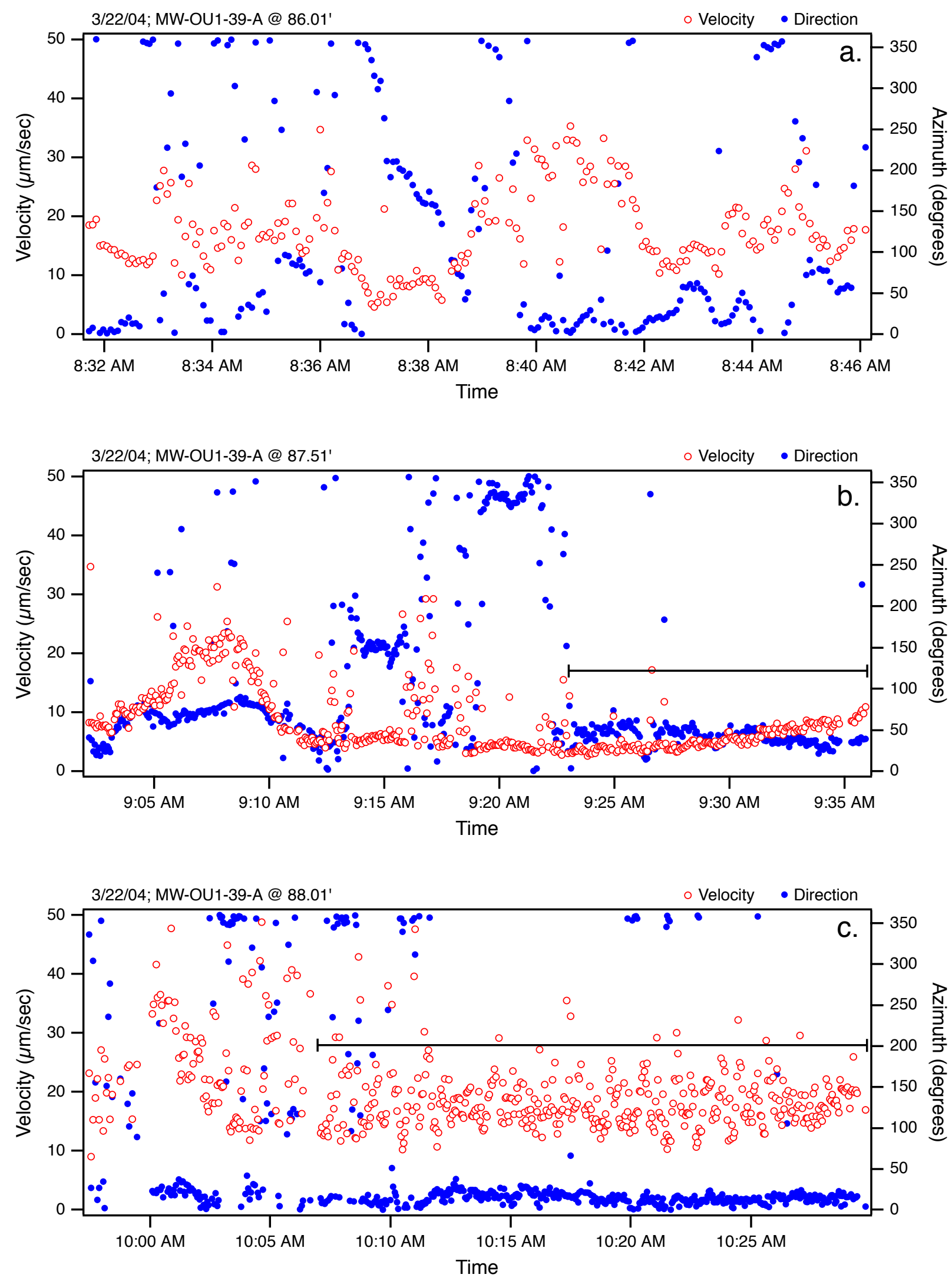

Figure 17. Groundwater flow rates and azimuth estimates derived from SCBFM image analysis. Horizontal bars indicate regions of stable particle flow rate and direction, from which numerical estimates could be made. Measurements from MW-OU1-39-A at: 86.01' '(a.), 87.51' (b.), and 88.01'(c.) below the ground surface. 

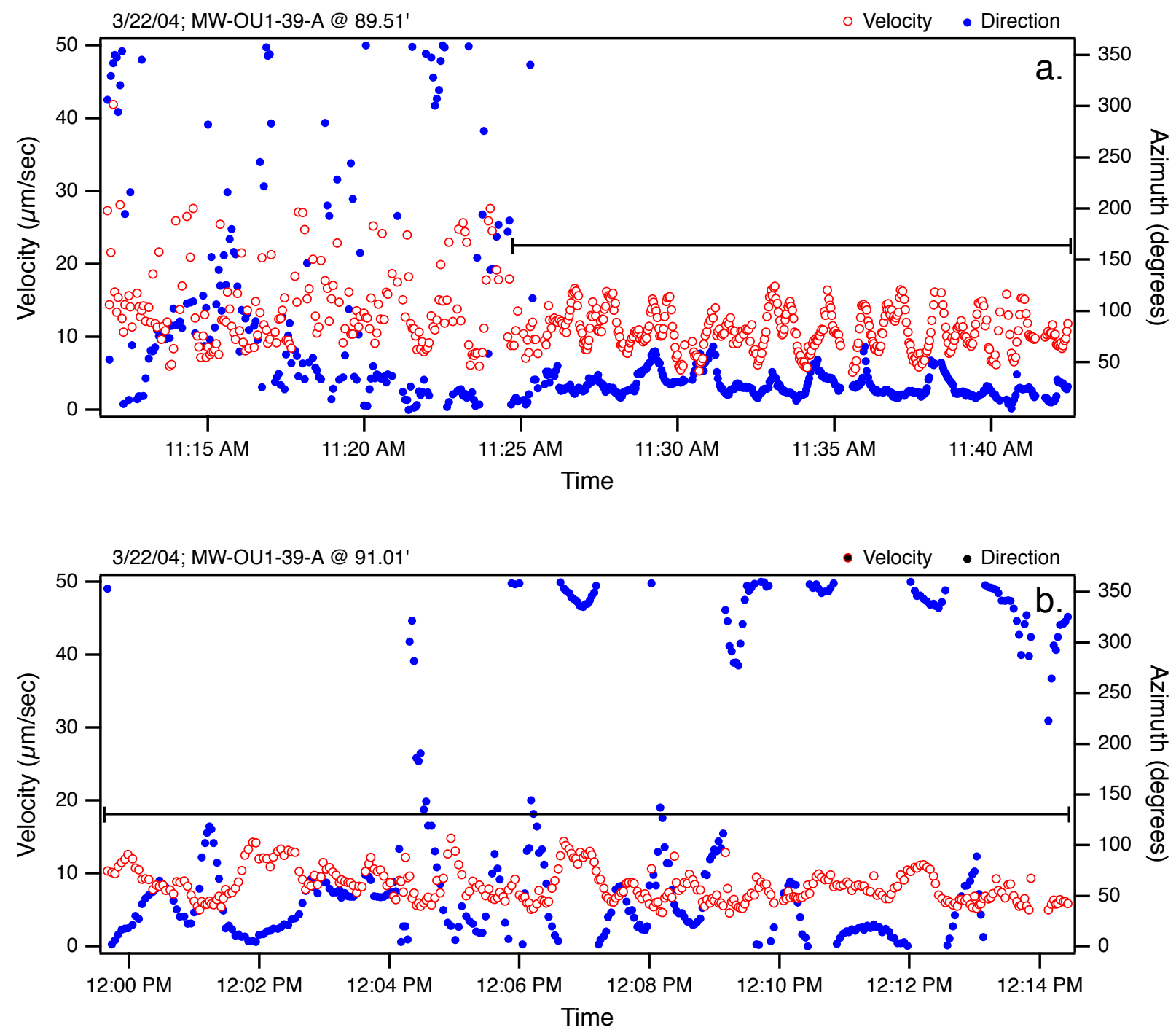

Figure 18. Groundwater flow rates and azimuth estimates derived from SCBFM image analysis. Horizontal bars indicate regions of stable particle flow rate and direction, from which numerical estimates could be made. Measurements from MW-OU1-39-A at: 89.51' (a.) and 91.01' (b.) below the ground surface. 